\title{
An IAEA multi-technique $X$-ray spectrometry endstation at Elettra Sincrotrone Trieste: benchmarking results and interdisciplinary applications
}

Andreas Germanos Karydas, Mateusz Czyzycki, Juan José Leani, Alessandro Migliori, Janos Osan, Mladen Bogovac, Pawel Wrobel, Nikita Vakula, Roman Padilla-Alvarez, Ralf Hendrik Menk, Maryam Ghahremani Gol, Matias Antonelli, Manoj K Tiwari, Claudia Caliri, Katarina Vogel-Mikuš, Iain Darby and Ralf Bernd Kaiser

J. Synchrotron Rad. (2018). 25, 189-203

\section{IIUCr Journals CRYSTALLOGRAPHY JOURNALS ONLINE \\ Copyright (C) International Union of Crystallography \\ Author(s) of this paper may load this reprint on their own web site or institutional repository provided that this cover page is retained. Republication of this article or its storage in electronic databases other than as specified above is not permitted without prior permission in writing from the IUCr. \\ For further information see http://journals.iucr.org/services/authorrights.html}


JOURNAL OF SYNCHROTRON RADIATION

ISSN 1600-5775

Received 1 July 2017

Accepted 13 November 2017

Edited by P. A. Pianetta, SLAC National Accelerator Laboratory, USA

Keywords: X-ray fluorescence; grazing incidence; X-ray reflectometry; X-ray absorption spectroscopy; beamline endstation.

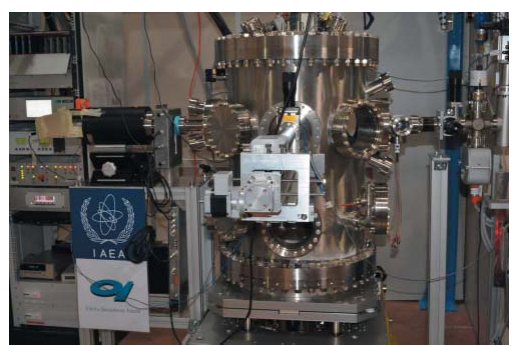

(C) 2018 International Union of Crystallography

\section{An IAEA multi-technique $X$-ray spectrometry endstation at Elettra Sincrotrone Trieste: bench- marking results and interdisciplinary applications}

\author{
Andreas Germanos Karydas, ${ }^{a, b *}$ Mateusz Czyzycki, ${ }^{a, c}$ Juan José Leani, ${ }^{\text {d,a }}$ \\ Alessandro Migliori, ${ }^{a}$ Janos Osan, ${ }^{\text {a,e }}$ Mladen Bogovac, ${ }^{a}$ Pawel Wrobel, \\ Nikita Vakula, ${ }^{a}$ Roman Padilla-Alvarez, ${ }^{a}$ Ralf Hendrik Menk, ${ }^{\mathrm{f}, \mathrm{g}}$

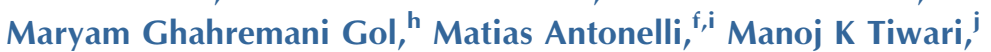 \\ Claudia Caliri, ${ }^{i}$ Katarina Vogel-Mikuš, ${ }^{k}, \mathbf{l}$ lain Darby ${ }^{a}$ and Ralf Bernd Kaiser ${ }^{a}$
}

${ }^{a}$ Nuclear Science and Instrumentation Laboratory, International Atomic Energy Agency (IAEA) Laboratories, A-2444 Seibersdorf, Austria, ${ }^{\mathbf{b}}$ Institute of Nuclear and Particle Physics, National Centre for Scientific Research 'Demokritos', Patr. Grigoriou E' \& 27 Neapoleos St, 15341 Agia Paraskevi, Greece, 'AGH University of Science and Technology, Faculty of Physics and Applied Computer Science, Al. A. Mickiewicza 30, 30-059 Krakow, Poland, dUIFEG, National Scientific and Technical Research Council (CONICET), Córdoba X5000HUA, Argentina,

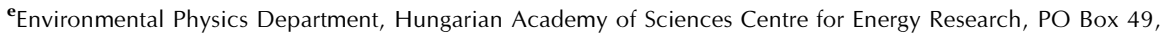
H-1525 Budapest, Hungary, 'Elettra-Sincrotrone Trieste SCpA di Interesse Nazionale, 34149 Basovizza, Trieste, Italy,

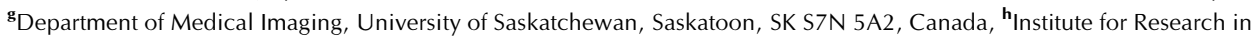
Fundamental Sciences (IPM), Iranian Light Source Facility (ILSF), Larak Building (Garden), PO Box 19568-36484, Tehran, Iran, 'Laboratori Nazionali del Sud, INFN, Via Santa Sofia 62, Catania 95123, Italy, '̇Synchrotrons Utilization Section, Raja Ramanna Centre for Advanced Technology, Indore 452013, Madhya Pradesh, India, kiotechnical Faculty, University of Ljubljana, Jamnikarjeva 101, Ljubljana, Slovenia, and 'Jozef Stefan Institute, Jamova 39, SI-1000 Ljubljana, Slovenia. *Correspondence e-mail: karydas@inp.demokritos.gr

The International Atomic Energy Agency (IAEA) jointly with the Elettra Sincrotrone Trieste (EST) operates a multipurpose X-ray spectrometry endstation at the X-ray Fluorescence beamline $(10.1 \mathrm{~L})$. The facility has been available to external users since the beginning of 2015 through the peer-review process of EST. Using this collaboration framework, the IAEA supports and promotes synchrotron-radiation-based research and training activities for various research groups from the IAEA Member States, especially those who have limited previous experience and resources to access a synchrotron radiation facility. This paper aims to provide a broad overview about various analytical capabilities, intrinsic features and performance figures of the IAEA X-ray spectrometry endstation through the measured results. The IAEA-EST endstation works with monochromatic X-rays in the energy range 3.7-14 keV for the Elettra storage ring operating at 2.0 or $2.4 \mathrm{GeV}$ electron energy. It offers a combination of different advanced analytical probes, e.g. X-ray reflectivity, $\mathrm{X}$-ray absorption fine-structure measurements, grazing-incidence X-ray fluorescence measurements, using different excitation and detection geometries, and thereby supports a comprehensive characterization for different kinds of nanostructured and bulk materials.

\section{Introduction}

The comprehensive characterization of modern, complex materials of importance in various scientific and technological fields requires the gathering and correlating of analytical information obtained from different probes, techniques or methodologies. The integration of different analytical capabilities in a single experimental facility is even more demanding and advantageous when it is applied in conjunction with synchrotron radiation (SR) sources, which are typically oversubscribed infrastructures. X-ray fluorescence (XRF) analysis is, for example, a rather simple analytical 
technique in terms of its application and interpretation offering qualitative and quantitative elemental information. Thanks to the tunability and the polarization of SR beams, SR-XRF analysis can offer ultra-low detection limits (Sparks, 1980). When SR is efficiently focused, high-brilliance microbeams (Janssens et al., 2004; Adams et al., 1998; Somogyi et al., 2005) or even nowadays nano-beams with sizes down to 40$50 \mathrm{~nm}$ (Winarski et al., 2012) can be produced offering an outstanding sensitivity for XRF investigations of metal traces at the nanometre scale (Lemelle et al., 2017). For example, using a high flux density exceeding $10^{13}$ photons s ${ }^{-1} \mu \mathrm{m}^{-2}[$ e.g. at the ESRF ID22NI nanoprobe beamline using bent Kirkpatrick-Baez (KB) multi-layer mirrors], even a few thousand atoms of transition metals can be detected at a spatial resolution of $\sim 90 \mathrm{~nm}$ (Adams et al., 2011). The development of fast, new-generation array X-ray detection systems processing high count rates and coupled with on-the-fly scanning stages (Lombi et al., 2011), the use of external total reflection irradiation geometry (total-reflection X-ray fluorescence, TXRF) for surface-sensitive analysis (Streli et al., 2008; Meirer et al., 2010; Fittschen et al., 2016; Singh et al., 2017) and the application of polycapillary optics to allow depth-resolved and eventually three-dimensional elemental analysis (3D- $\mu \mathrm{XRF}$ ) of structured materials (Kanngießer et al., 2003; Janssens et al., 2004) or of buried inclusions in diamonds (Vincze et al., 2004) have significantly improved the analytical merits and the importance of SR-XRF analysis in various applications of emerging interest. When SR-XRF analysis is applied at beamlines with suitable monochromators offering high energy resolution $\left(\leq 10^{-4}\right)$ and spectral purity, the X-ray absorption fine-structure (XAFS) methodology offers additional unique information on the oxidation state, chemical environment and local symmetry of the sample constituent atoms. TXRF and in particular SR-TXRF paved the way for ultra-trace-sensitive surface elemental analysis with numerous environmental, biomedical and industrial applications, such as controlling for example the level of impurities on large $300 \mathrm{~mm}$ Si wafers down to $1 \times 10^{8} \mathrm{Ni}$ atoms $\mathrm{cm}^{-2}$ (Beckhoff et al., 2007; Beckhoff, 2008). The ongoing development needs a better characterization, understanding and even tailored functional performance of structured modern materials, used in energy storage and conversion technologies, micro- and nano-electronics, in biosensor technologies and nano-medicine design. In order to fulfil these tasks, probes and analytical methodologies are required that can offer a nanometre-range indepth resolution for elemental and chemical state analysis in a wide dynamic range from about one to a few hundreds of nanometres. In this respect, the revisiting and the utilization of remarkable properties of the X-ray standing wave (XSW) field formed above the reflecting surface of single or multi-layered thin films with nanometre-scale intensity modulations under grazing incidence (GI) conditions has supported numerous instrumentation developments and analytical applications (de Boer et al., 1995; Leenaers \& de Boer, 1997; Krämer et al., 2006; von Bohlen, 2009; Tiwari et al., 2013; Lubeck et al., 2013, 2016; Spanier et al., 2016; Ménesguen et al., 2017). By varying continuously the grazing incident angle through and a few times above the critical angle for external total reflection, the recorded XRF intensity profiles (GIXRF analysis) have a certain potential to reflect and to provide information on the structural and compositional properties of thin films, such as the layer composition, sequence, thicknesses and densities, interface roughness, in-depth elemental gradients of matrix elements or dopants in semiconductors, the characterization of nano-particles deposited on flat surfaces etc. Although a more accurate and robust reconstruction of these thin film properties requires the synergy or even the simultaneous fitting of GIXRF with X-ray reflectometry (XRR) data (Ingerle et al., 2014; Yang et al., 2013; Das et al., 2015), GIXRF analysis is particularly useful and important when the XRR information is limited, as in the case of ultra-thin (sub-nm to a few nm thickness) or very thick (>100 nm) layers (Das et al., 2015). The possibility to perform a combined GIXRF, XRR and XSW-assisted XAFS analysis at SR sources, in particular by investigating the near-edge part of the absorption spectrum in the tender (X-ray absorption near-edge structure, XANES) or soft (near-edge X-ray absorption fine structure, NEXAFS) regimes can further support interfacial studies, including diffusion and chemical specificity of buried nano-layers (Pagels et al., 2010; Becker et al., 2013; Pollakowski et al., 2013).

The International Atomic Energy Agency (IAEA) through its program activities, such as Coordinated Research Projects (http://cra.iaea.org/cra/), promotes and supports interdisciplinary research at various SR facilities. Moreover, since the access to synchrotron beam time is granted based on the scientific merit of proposals, for scientists who originate from countries without the availability of such large infrastructures, the IAEA develops and fosters relevant expertise and scientific competence by organizing, with the valuable support of International Centre for Theoretical Physics (ICTP) in Trieste and of Elettra Sincrotrone Trieste, dedicated workshops and training schools.

In this framework, in 2013 the IAEA established a close collaboration with EST for the commissioning and operation of the newly constructed X-ray Fluorescence (XRF) beamline in conjunction with an advanced multi-purpose X-ray spectrometry (XRS) instrument developed by the IAEA (IAEAXspe). The IAEAXspe beamline endstation is based on a prototype instrument designed and built by the Physikalisch-Technische Bundesanstalt (PTB) and Technische Universität Berlin (TUB) (Lubeck et al., 2013, 2016). The IAEAXspe instrument offers, keeping the feature of being non-destructive and non-preparative, sequential or combined multi-technique analysis of a sample by means of sub-millimetre XRF imaging, XANES, TXRF, GIXRF-XRR, TXRFXANES and GI-XANES after adjusting and tuning properly experimental parameters such as: the incident beam energy and the coordinates of an advanced seven-axis sample/ photodiodes manipulator, that allows to align and move the sample and a series of photodiodes with five and two degrees of freedom, respectively.

The synchrotron beamlines which can offer TXRF and GIXRF analyses number less than ten worldwide (Awaji, 2004; 
Awaji et al., 2000; Beckhoff et al., 2007; Hirai et al., 2004; Krywka et al., 2007; Maurizio et al., 2009; Ohashi et al., 2013; Riesemeier et al., 2005; Terada et al., 2011; Yuying et al., 2001; Ménesguen et al., 2017; Tiwari et al., 2013), whereas much fewer can support a combined application of those techniques with XANES or/and XRR (Beckhoff et al., 2007; Maurizio et al., 2009; Ohashi et al., 2013; Terada et al., 2011; Uruga et al., 1999; Tiwari et al., 2013; Ménesguen et al., 2017). A dedicated TXRF-XANES setup has been recently commissioned at BESSY II BAMline and respective figures of merit and first applications have been reported (Fittschen et al., 2016). On the other hand, XRR is quite popular as it is available at $16 \mathrm{SR}$ beamlines. Table 1 reports synchrotron radiation beamlines worldwide where angle-resolved X-ray spectrometry techniques, such as TXRF, GIXRF/GEXRF and XRR, are available or are in conjunction with X-ray absorption spectrometry. The main fields of research applications are: materials sciences (including thin films, surfaces, interfaces and industrial materials), environmental and life sciences along with biomedicine. The instrumental features of these beamlines are quite different, in terms of the type of SR source used (bending magnets and insertion devices), monochromators (mostly $\mathrm{Si}$ crystals cut at different planes), focusing devices for producing micro-beams (mostly KB mirrors, Fresnel zone plates and also polycapillary lenses) and energy-dispersive detectors [including single $\mathrm{SDD}, \mathrm{Si}(\mathrm{Li}), \mathrm{HPGe}$ as well as detector arrays and diodes]. Recent instrumentation developments and technology transfer by the PTB at the electron storage ring BESSY II, focused to support the application of advanced XRS techniques at SR sources and in the laboratory environment, are briefly summarized by Lubeck et al. (2016). In particular, the novel nine-axis PTB sample manipulator (Lubeck et al., 2013) offers additional degrees of freedom enabling polarization-dependent XAFS and XRF analyses. The instrument can be operated at the plane-grating monochromator (PGM) and the four-crystal monochromator (FCM) beamlines which provide high-spectral purity and high photon flux in the energy ranges from $78 \mathrm{eV}$ to $1.86 \mathrm{keV}$ and from $1.75 \mathrm{keV}$ to $10.5 \mathrm{keV}$, respectively, and has been utilized in numerous applications (Eisenhauer et al., 2015; Hönicke et al., 2015). An interesting development of a relevant experimental beamline facility has also been reported at the Indus-2 synchrotron radiation source (Tiwari et al., 2013). Using a bending-magnet source the beamline operates in the X-ray energy range $4-20 \mathrm{keV}$ providing a collimated incident beam and a micro-focused beam with KB mirrors. In this way, different analytical techniques are also supported, including micro-XRF imaging and combined GIXRF and XRR analysis (Das et al., 2015).

The IAEA-EST joint SR beamline facility started its regular user operation mode at the beginning of 2015 and then subsequently various research programs within the IAEA Coordinated Research Project (CRP) G42005 have been initiated to enhance the user base of the facility. The research areas of interest include materials sciences (and in particular the characterization of nano-structured materials, materials
Table 1

SR beamlines worldwide, where angle-resolved X-ray spectrometry techniques, such as TXRF, GIXRF/GEXRF and XRR are available or in conjunction with X-ray absorption spectrometry.

\begin{tabular}{|c|c|c|}
\hline SR facility & Beamline & $\begin{array}{l}\text { Available techniques with } \\
\text { references }\end{array}$ \\
\hline \multirow[t]{2}{*}{ SSRL (Stanford) } & $7-2,10-2 B$ & XRR \\
\hline & $11-2$ & TXRF-XAS, GIXAS \\
\hline \multirow[t]{7}{*}{ SPring-8 } & BL08B2 & XRR \\
\hline & BL16XU & $\begin{array}{l}\text { XRR, TXRF, GIXRF, GEXRF } \\
\quad \text { (Awaji, 2004; Hirai } \text { et al., 2004) }\end{array}$ \\
\hline & BL16B2 & XRR (Hirosawa et al., 2004) \\
\hline & BL19B2 & XRR (Hirosawa et al., 2011) \\
\hline & BL46XU & XRR \\
\hline & BL37XU & $\begin{array}{l}\text { TXRF, GIXRF, GEXRF, TXRF- } \\
\text { XAS, GIXAS (Ohashi et al., } \\
\text { 2013; Terada et al., 2011) }\end{array}$ \\
\hline & BL01B1 & $\begin{array}{l}\text { TXRF-XAS, GIXAS (Uruga et al., } \\
\text { 1999) }\end{array}$ \\
\hline \multirow[t]{2}{*}{ ESRF } & BM32 & XRR (Ulrich et al., 2011) \\
\hline & BM08 & $\begin{array}{l}\text { TXRF, GIXRF, GEXRF, TXRF- } \\
\text { XAS, GIXAS (Maurizio et al., } \\
\text { 2009) }\end{array}$ \\
\hline \multirow[t]{2}{*}{ BESSY II } & BAMline & $\begin{array}{l}\text { XRR, TXRF, GIXRF GEXRF } \\
\text { (Riesemeier et al., 2005; } \\
\text { Fittschen } \text { et al., 2016) }\end{array}$ \\
\hline & РTB & $\begin{array}{l}\text { TXRF, GIXRF, GEXRF, TXRF- } \\
\text { XAS, GIXAS, XRR (Beckhoff } \\
\text { et al., 2007) }\end{array}$ \\
\hline \multirow[t]{2}{*}{ Beijing Synchrotron } & $1 \mathrm{~W} 1 \mathrm{~A}$ & XRR \\
\hline & $4 \mathrm{~W} 1 \mathrm{~B}$ & $\begin{array}{l}\text { TXRF, GIXRF, GEXRF (Yuying } \\
\text { et al., 2001) }\end{array}$ \\
\hline Taiwan Synchrotron & BL17B1 & $\begin{array}{l}\text { XRR, TXRF, GIXRF, GEXRF } \\
\text { (Chang et al., 2004) }\end{array}$ \\
\hline \multirow[t]{4}{*}{ Brazilian Synchrotron } & DXAS & XRR (Cezar et al., 2010) \\
\hline & XAFS1 & XRR (Tolentino et al., 1998, 2001) \\
\hline & XAFS2 & XRR \\
\hline & XRF & TXRF, GIXRF, GEXRF \\
\hline Indus-2 & BL-16 & $\begin{array}{l}\text { XRR, TXRF, GIXRF, GEXRF, } \\
\text { TXRF-XAS, GIXAS (Tiwari et } \\
\text { al., 2013; Das et al., 2015) }\end{array}$ \\
\hline Delta & BL-9 & $\begin{array}{l}\text { XRR, TXRF, GIXRF, GEXRF } \\
\text { (Krywka et al., 2007, 2006; } \\
\text { Paulus et al., 2008) }\end{array}$ \\
\hline ANKA & FLUO & $\begin{array}{l}\text { TXRF, GIXRF, GEXRF (Simon et } \\
\text { al., 2003) }\end{array}$ \\
\hline Swiss Light Source & X05DA & $\begin{array}{l}\text { TXRF-XAS, GIXAS, XRR } \\
\text { (Kayser et al., 2015) }\end{array}$ \\
\hline Soleil & CASTOR & $\begin{array}{l}\text { TXRF-XAS, GIXAS, XRR } \\
\text { (Ménesguen et al., 2017) }\end{array}$ \\
\hline
\end{tabular}

for solar cells), the characterization of environmental samples (airborne particulate matter, water samples, suspensions, coal fly ash), biomedicine (speciation of trace elements in human tissues for cancer studies), biology (study of essential or toxic elements in plants to develop/improve biofortification, phytoremediation and phyto-mining techniques), preventive conservation and study of ancient technologies of manufacture, and systematic measurement and re-evaluation of X-ray fundamental parameters. This paper aims to describe the commissioning results obtained from various instruments of the IAEAXspe endstation installed at the XRF beamline of Elettra and to demonstrate overall analytical features and capabilities of the facility by exploring some exemplary interdisciplinary applications. 


\section{Experimental}

\subsection{The XRF beamline at Elettra Sincrotrone Trieste}

The XRF beamline is a bending-magnet beamline at the third-generation Elettra storage ring that operates at two different energy modes: $2 \mathrm{GeV}$ (critical energy of $3.21 \mathrm{keV}$ ) and $2.4 \mathrm{GeV}$ (critical energy of $5.59 \mathrm{keV}$ ). The XRF beamline currently provides an energy range for the incident beam from about 3.7 to $14 \mathrm{keV}$ by means of a double-crystal $\mathrm{Si}(111)$ monochromator with a resolving power of about $1.5 \times 10^{-4}$. The primary beam at the sample position is currently shaped by exit slits to a beam size of about $200 \mu \mathrm{m} \times 100 \mu \mathrm{m}(\mathrm{H} \times \mathrm{V})$. Additional monochromators (InSb as well as different multilayer monochromators) have been installed and are currently under commissioning to extend the analytical range for tunable excitation energies even below $1 \mathrm{keV}$ and for XAFS measurements from 2.0 to $3.7 \mathrm{keV}$. A detailed description of the beamline optical system can be found elsewhere (Jark et al., 2014).

\subsection{The IAEAXspe instrument hardware components}

2.2.1. Ultra-high-vacuum (UHV) endstation chamber. The endstation consists of a cylindrical chamber with a diameter of $500 \mathrm{~mm}$ and a height of $774 \mathrm{~mm}$ (inner dimensions). This main chamber can operate at a pressure range lower than $10^{-8}$ mbar and it is equipped with a secondary UHV load lock attached in cross configuration. By a magnetically coupled transporter system the exchange of samples can be performed maintaining the low pressure inside the main chamber. The main and load lock UHV chambers were both constructed following a design made jointly by the PTB and the TUB (Lubeck et al., 2013; Spanier et al., 2016). The chamber is equipped with a number of different side flanges placed at two horizontal levels allowing the integration of different instrumentation. Moreover, the top cover plate is equipped with a number of auxiliary flanges as well. The main chamber is directly connected to the beamline downstream; however, the isolation of the chamber vacuum environment can be achieved by the insertion of a thin beryllium window. In this way, highly degassing and generally non-UHV-compatible samples can also be analysed. An overall picture of the IAEAXspe instrument is shown in Fig. 1(a).

2.2.2. Seven-axis manipulator. The motorized seven-axis manipulator (Huber Diffraktionstechnik $\mathrm{GmbH}$ ) is composed of four linear stages and three rotational axes used to provide a proper orientation of the analyzed sample surface and/or monitoring detectors as required by the experiment to be conducted. In particular, the sample manipulation allows three translations $(X, Y, Z)$ perpendicular to each other and a rotation around two perpendicular axes (Theta and Phi). An additional rotational axis (2Theta) and a linear stage (Diode) are used for the movement of the arm holding the X-ray detection systems with respect to the direction of the SR beam or/and sample surface. The movement of all axes is illustrated in Fig. 1(b), whereas Fig. 1(c) depicts the possible angular range for the two (Theta, 2Theta) goniometers.

Theta/2Theta rotational axes are provided by a two-circle goniometer mounted on a ground plate fixed on the base of the main chamber. An encoder is used to check the Theta-axis reading, whereas the diode axis is mounted at the end of the 2Theta goniometer arm. The linear stage $Z$ is placed on the top and perpendicular to the Theta rotational axis. In addition, the $Z$ axis holds the Phi circle goniometer that it is attached in such a way that its rotational axis is parallel to $Z$. Finally, the $X Y$ linear stage (onto which the sample is placed) is installed onto the Phi axis to allow two-dimensional scanning measurements of the sample surface, as well as rotational Phi alignment across the beam direction of samples exhibiting a particular geometry (for example, thin slices). Both $X$ and $Y$ axes are perpendicular to the rotational axis of the Phi goniometer as well as to the linear stage $Z$. The rotational axis of Phi goes through the center of the $X Y$ stage.

The functional performance of all linear and rotational stages was evaluated during a first commissioning phase by PTB at BESSY II with the use of an autocollimator system ELCOMAT 3000 (Moller-Wedel Optical GmbH). The

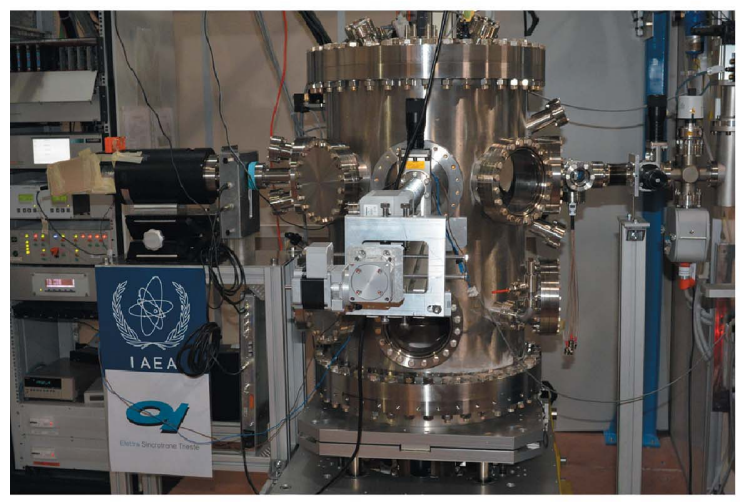

(a)

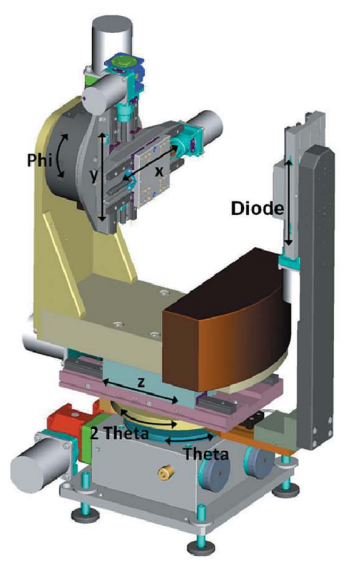

(b)

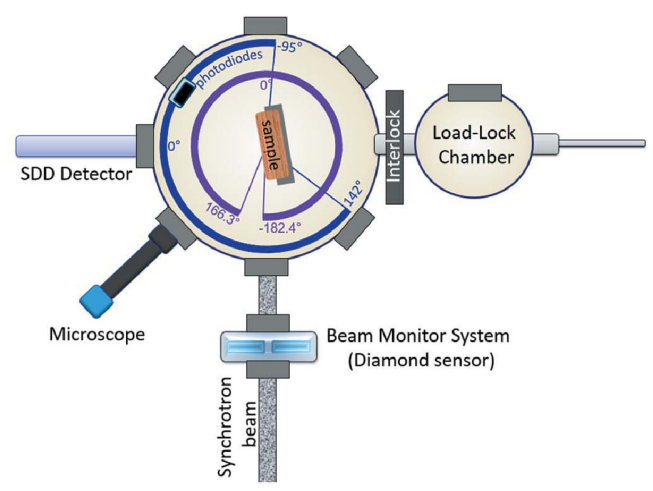

(c)

Figure 1

(a) Photograph of the IAEAXspe instrument installed at the XRF beamline of Elettra Sincrotrone Trieste (C) Iain Darby/IAEA). (b) Seven-axis motorized manipulator. (Artwork courtesy of Huber Diffraktionstechnik GmbH \& Co. KG.) (c) Movement range of Theta/2Theta axes depicted in a horizontal cross-sectional view of the IAEA endstation. 
repeatability and reversal errors for the rotational Theta, 2Theta and Phi axes were determined to be less than 10 arcsec, whereas the yaw, pitch and roll for the three translational axes $X, Y$ and $Z$ to be less than 30 arcsec (Lubeck et al., 2015).

2.2.3. Base system. The chamber is mounted on a movable motorized welded steel base frame which allows a fine alignment of the instrument versus the incident SR beam. The movement can be performed in two axes of translation and a single rotational axis. It allows the position of the chamber to be adjusted vertically $( \pm 50 \mathrm{~mm})$, horizontally (perpendicularly to the beam direction, $\pm 12 \mathrm{~mm}$ ) and rotationally around the chamber axis $\left( \pm 5^{\circ}\right)$.

2.2.4. Energy-dispersive detectors. The XRF measurements are performed using a silicon drift detector (SDD) (Bruker Nano GmbH, XFlash 5030), which is placed on the incidentbeam horizontal plane, perpendicular to the primary beam. This SDD has a $30 \mathrm{~mm}^{2}$ nominal crystal area (which however is restricted down to about $25 \mathrm{~mm}^{2}$ due to the use of a $\mathrm{Zr}$ collimator placed around its perimeter), a thickness of $450 \mu \mathrm{m}$, nominal resolution equal to $131 \mathrm{eV}$ (at $\mathrm{Mn}-K \alpha$ ), and is equipped with a Super Light Element Window (SLEW; Bruker Nano GmbH). The SLEW is composed of an ultrathin polymer covered by an Al layer with a thickness of few tens of nanometres mounted on a silicon grid with $\sim 77 \%$ transmission up to about $8 \mathrm{keV}$. The SDD is coupled with a magnetic photoelectron trap to prevent the detection of photoelectrons or Auger electrons ejected by the analysed sample. Two Al apertures with respective diameters of $2.25 \mathrm{~mm}$ and $4.7 \mathrm{~mm}$ inserted at both sides of the photoelectron trap (length about $14.2 \mathrm{~mm}$ ) ensure that no parasitic line from the magnet elements will be detected, whereas the incoming X-rays are detected within the central region of the SDD sensor.

When the detection of characteristic X-rays below 1.5$2 \mathrm{keV}$ is not of particular interest for the conducted XRF or TXRF experiment, the magnetic trap can be substituted by a $\sim 8.5 \mu \mathrm{m}$ beryllium window providing an adequate thickness to absorb energetic electrons up to $15 \mathrm{keV}$. The advantage of this configuration is that it improves considerably the solid angle of detection by more than a factor of three. The detector intrinsic efficiency calculated for two different window configurations (SLEW; SLEW and Be) is presented in Fig. 2. The SDD output signal is processed by a digital signal processing unit (MIN SVE, Bruker Nano GmbH) providing a detector bias supply, pile-up rejection, input/output count-rate meter, selectable shaping time constants and dead-time correction using an internal electronic generated peak ('zero' peak) with adjustable frequency. The relative low noise of the SDD $(59.9 \mathrm{eV})$ allows the detection of soft X-rays down to $\mathrm{C}-K \alpha(277.4 \mathrm{eV})$. Fig. 3 presents the low-energy part of the RMX10 (defined later) XRF spectrum excited by a $3.8 \mathrm{keV}$ incident X-ray beam with the front aperture of the photoelectron trap SDD placed at a distance of $17 \mathrm{~mm}$ from the sample. The spectrum was acquired for $535 \mathrm{~s}$ and it was fitted using the PyMca software package (Solé et al., 2007). Char-

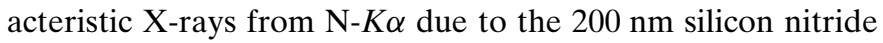
substrate, and several $L \mathrm{X}$-ray lines of transition metals ( $\mathrm{Ti}$, $\mathrm{Cr}, \mathrm{Ni}$ and $\mathrm{Cu}$ ) are shown together with $\mathrm{Al}-K \alpha$ and $\mathrm{Si}-K \alpha$

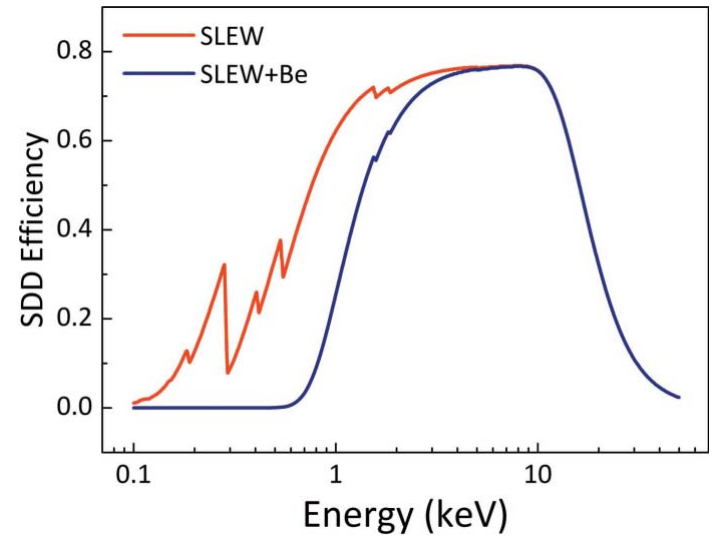

Figure 2

Intrinsic efficiency of the Bruker SDD at the two different window configurations (SLEW; SLEW with an $8.5 \mu \mathrm{m}$ Be window). The SLEW data are provided by Bruker Nano Analytics.

characteristic X-rays. A low-intensity $\mathrm{O}-K \alpha$ peak is due to partial oxidation of the front $\mathrm{Cr}$ layer.

An additional miniaturized and UHV-compatible SDD (Amptek Inc., FAST-SDD, PA-210 package configuration) can be placed on the motorized arm that includes the 2 Theta and diode axes to extend the dynamic range for XRR measurements. This SDD has a $25 \mathrm{~mm}^{2}$ nominal active area, $500 \mu \mathrm{m}$ sensor thickness, $8 \mu \mathrm{m} \mathrm{Be}$ window, nominal resolution equal to $125 \mathrm{eV}($ at $\mathrm{Mn}-\mathrm{K} \alpha)$ and it can be operated at input count rates up to 1 Mcps (cps = counts per second). The output signal is processed by the PX5 unit (Amptek Inc.) that includes a digital pulse processor and a multichannel analyser.

2.2.5. X-ray beam intensity detectors. The beam transmitted or reflected by the sample can be monitored by a set of five photodiodes, a Hamamatsu Si-S3590-09 without (PD1) and with $100 \mu \mathrm{m}$ (PD4) and $200 \mu \mathrm{m}$ (PD5) vertical slits, respectively, a Si SXUV100 by Opto Diode (PD2) and a GaAsP G1126-02 by Hamamatsu (PD3), mounted on the motorized vertical arm. A picoammeter (Keithley, 6485)

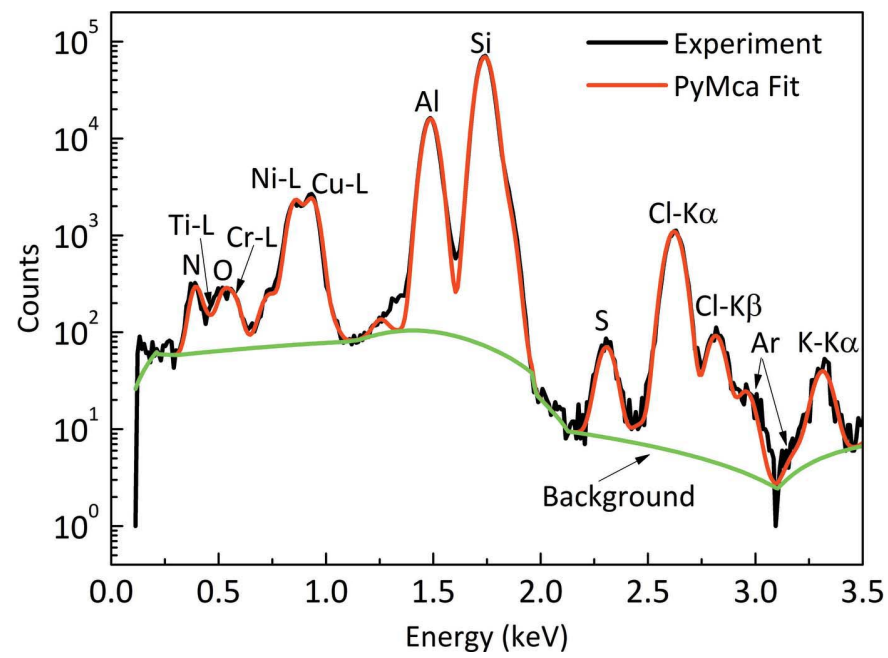

Figure 3

Fitting of the XRF spectrum of the RMX10 multilayer thin film $(\mathrm{Cr} / \mathrm{Al} /$ $\mathrm{Ni} / \mathrm{Cu} / \mathrm{Ti})$ deposited on $200 \mathrm{~nm}$ silicon nitride membrane $\left(\mathrm{Si}_{3} \mathrm{~N}_{4}\right)$ measured at $3.8 \mathrm{keV}$ excitation energy collected with the Bruker SDD. 
is utilized for photocurrent measurements operated at a constant integration time of $100 \mathrm{~ms}$ (the best noise performance) with the number of measurements stored depending on the preset real-time of the energy-dispersive detector.

The intensity of the incoming beam is monitored by a beam monitoring system (BMS) developed by the detector group of Elettra Sincrotrone Trieste. The heart of this system is a fourchannel solid-state sensor composed of a $12 \mu \mathrm{m}$-thick freestanding polycrystalline chemical vapor deposit ( $\mathrm{pVCD}$ ) diamond plate (Dectris, Rigi). Its total active area is $9 \mathrm{~mm} \times$ $3 \mathrm{~mm}$ subdivided into four electrodes of $4.5 \mathrm{~mm} \times 1.5 \mathrm{~mm}$ area each (separated by a gap of about $20 \mathrm{~nm}$ ) connected with individual UHV feedthroughs to the signal processing and acquisition system. The very small thickness of the diamond sensor and composed materials (electrodes and backplane composed of $\mathrm{Ti} / \mathrm{Al}$ with $15 \mathrm{~nm}$ and $100 \mathrm{~nm}$ thicknesses, respectively) allows good transmission at low energies $(67.4 \%$ at $3.0 \mathrm{keV})$. The diamond detector can be inserted or retracted from the beam path using a manually controlled linear stage. The individual currents from the four sensors are registered by a four-channel picoammeter (Elettra, AH501B).

2.2.6. Auxiliary components. The sample environment can be monitored online by two independent colour cameras. The macro camera (Lumenera, Lw235C) with $\sim 5 \mathrm{~cm} \times 5 \mathrm{~cm}$ field of view helps to preview the sample surroundings, whereas the micro camera (PCO Pixelfly) coupled with a long-distance microscope (Infinity, K2/SC DistaMax, CF-1/B) provides a field of view of $\sim 1 \mathrm{~mm} \times 1.5 \mathrm{~mm}$ and a preliminary sample alignment. An example of the sample environment preview is shown in Fig. 4 during the analysis of decorated archaeological ceramics.

2.2.7. Sample environment. The samples can be measured in two different geometries mounted on respective holders. Using an Al-base holder designed by the PTB group at BESSY II up to seven samples of about $1-2 \mathrm{~cm}$ in diameter can be mounted and measured either at grazing-incidence geometry (for TXRF, GIXRF and XRR measurements) or at any other selected angle with respect to the incoming beam. The second Teflon (PTFE) based holder designed by the IAEA allows XRF and XANES measurements to be performed at fixed $45^{\circ} / 45^{\circ}$ geometry (i.e. both the incident beam and detector axis form an angle of $45^{\circ}$ with respect to the sample surface normal) allowing a simultaneous recording of the transmitted beam by any of the photodiodes (in the case when thin or semi-thin samples are analysed) and the XRF spectrum by the SSD. This sample holder offers the possibility to mount together about six to eight disc-shaped samples of $1 \mathrm{~cm}$ diameter.

2.2.8. Data acquisition and control system. All of the hardware components of the IAEAXspe endstation are controlled by the Tango control system which is organized in a two-level hierarchy. The low-level software modules (Tango Device Servers) communicate with the corresponding hardware components. The high-level module can communicate with all low-level components and is responsible for data acquisition from all hardware devices. It enables data to be acquired either in asynchronous mode or in synchronous

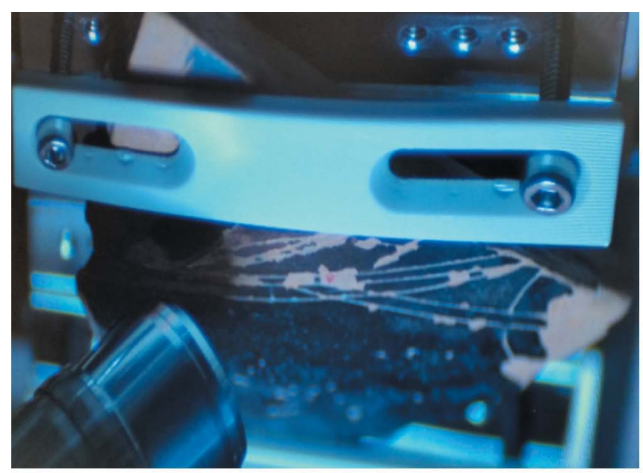

(a)

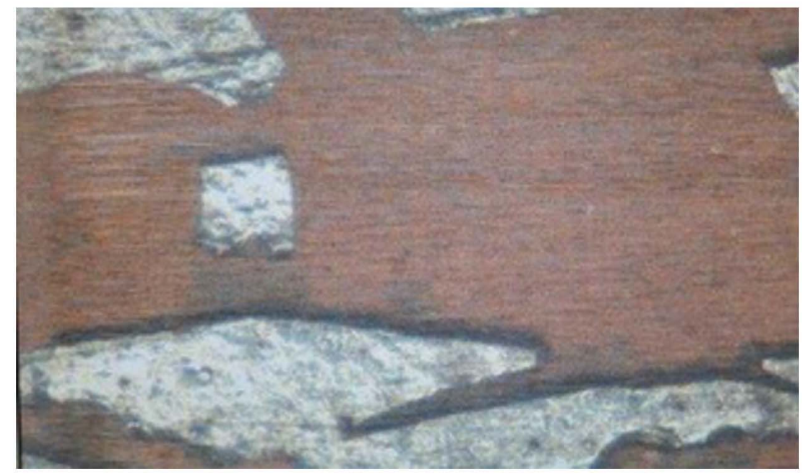

(b)

Figure 4

Example of the sample preview with macro $(a)$ and micro $(b)$ cameras inside the IAEAXspe endstation. In the bottom-left corner of $(a)$ a collimator appears on top of the SDD.

mode. In the latter case the data from different detectors are acquired synchronously with sample or/and detector movement allowing multi-dimensional scanning. All data are stored in ASCII text files and in HDF5 file format. The high-level module is controlled by a graphical user interface (GUI) developed in the LabVIEW graphical programming language. The GUI allows a single acquisition to be performed as well as single or multiple multi-dimensional scans in pre-defined order using a batch utility. Detailed information about the IAEA instrument control software can be found elsewhere (Wrobel et al., 2016).

\section{Commissioning results from the IAEAXspe beamline endstation}

\subsection{Materials and methods}

The characterization of the endstation instrumentation was facilitated by measuring in a fixed $45^{\circ} / 45^{\circ}$ geometry (using the PTFE sample holder described in \$2.2.7) a thin multi-layered reference material (Krämer et al., 2011) composed of different elements (Al, Ti, Cr, Ni and $\mathrm{Cu}$ ) deposited onto $200 \mathrm{~nm} \mathrm{Si}{ }_{3} \mathrm{~N}_{4}$ (before and hereafter referred to as RMX10). This sample was prepared by AXO Dresden $\mathrm{GmbH}$ and the sequence of the elements deposited and their respective areal densities are reported in Table 2. The RMX10 reference sample has been measured frequently over the last two years of beamline 
Table 2

Nominal and experimentally deduced areal densities (mass per unit area) of metallic elements deposited on a thin $200 \mathrm{~nm} \mathrm{Si} \mathrm{Si}_{4}$ membrane (reference material RMX10 manufactured by AXO Dresden GmbH).

The nominal mass deposits represent average values measured by TXRF and ICP-OES techniques. The Ti determination included a large uncertainty $(50 \%)$ and thus it is not reported.

\begin{tabular}{llll}
\hline Element & $\begin{array}{l}\text { Nominal } \\
\left(\mathrm{ng} \mathrm{cm}^{-2}\right)\end{array}$ & $\begin{array}{l}\text { Error } \\
\left(\mathrm{ng} \mathrm{cm}^{-2}\right)\end{array}$ & $\begin{array}{l}\text { Experimental } \\
\left(\mathrm{ng} \mathrm{cm}^{-2}\right)\end{array}$ \\
\hline $\mathrm{Cr}$ & 9210 & 100 & $9448(4 \%)$ \\
$\mathrm{Al}$ & 9020 & 100 & $10788(4 \%)$ \\
$\mathrm{Ni}$ & 9640 & 100 & $9704(4 \%)$ \\
$\mathrm{Cu}$ & 9700 & 230 & $9742(4 \%)$ \\
$\mathrm{Ti}$ & - & - & $8409(4 \%)$ \\
\hline
\end{tabular}

operation at different incident energies and Elettra storage ring operational modes for quantitative calibration of the setup and for checking the reproducibility of the experimental conditions determined to be at the level of $2 \%$. The analysis of RMX10 spectra for incident beam flux determination was carried out by means of the PyMca software package (version 5.1.2) that accounts properly for inter-element attenuation and secondary fluorescence phenomena. The PyMca configuration file was set up in order to account properly for the SDD efficiency (Fig. 2), whereas the solid angle was analytically described taking into account the exact geometry of the photoelectron trap assembly including the two defining apertures and the beam-SDD distance as deduced from an alignment procedure.

\subsection{Characterization of detectors}

Precision figures for the photocurrent recorded by the silicon photodiode PD1 and the diamond sensor (BMS) are reported in Fig. 5(a) for the energy regime from 4 to $14 \mathrm{keV}$ for the Elettra operation at $2 \mathrm{GeV}$. The precision of the measurement with the photodiode PD5 (same diode as PD1 but with a $200 \mu \mathrm{m}$ vertical slit in front) at different photocurrent values (from a few $\mathrm{pA}$ to the $\mu \mathrm{A}$ range) is also shown in Fig. 5(b). In all cases the standard deviation was determined from 200 consecutive measured values in the no-scan mode of the control software (Wrobel et al., 2016). As can be seen, a precision of generally less than $0.4 \%$ can be achieved at the dynamic range of incident fluxes provided by the $\mathrm{Si}(111)$ crystal monochromator. However, as we approach the PD1 dark noise level in the low $\mathrm{pA}$ range $(<10 \mathrm{pA})$, the precision in the photocurrent measurement is decreased substantially. This uncertainty is expected to influence mostly XRR measurements when the maximum possible dynamic range is required.

For quantitative analysis it is useful to estimate the variability of the photocurrent PD1 and BMS from a sequence of independent measurements. A precision better than $0.2 \%$ (represented by the standard deviation of the mean PD1, BMS values) can be obtained from scan measurements $\left(\sim 30\right.$ points $\operatorname{scan}^{-1}, \quad 10 \mathrm{~s}$ point $\left.^{-1}\right)$ performed within the energy regime $4-14 \mathrm{keV}$ at different operational modes of Elettra.
The thicknesses of the BMS sensor and Be filter were determined by using the $\mathrm{PD} 1$ readings in transmission measurements by tuning the incident energy from 3.8 to $5 \mathrm{keV}$. The RMX10 sample was also utilized simultaneously in the fixed $45^{\circ} / 45^{\circ}$ position helping to obtain very fine corrections at the level of $<2 \%$ thus accounting for source-based instabilities. A thickness of $(10.1 \pm 0.1) \mu \mathrm{m}$ was obtained for the thickness of the BMS sensor and $(17.0 \pm 1.2) \mu \mathrm{m}$ for the $\mathrm{Be}$ filter.

A systematic work was undertaken to determine the thicknesses of PD1 and PD2 monitor devices. This is a critical aspect of the experimental setup as a calibrated photodiode with respect to its thickness can provide an independent estimation regarding incident fluxes separately from any fluorescence measurement that involves the SDD. The analytical methodology that was used for the determination of the PD1 thickness consisted of registering at each incident energy the photocurrent values with PD1, BMS and measuring with the SDD the respective fluorescence intensities induced by the RMX10 sample that was positioned at

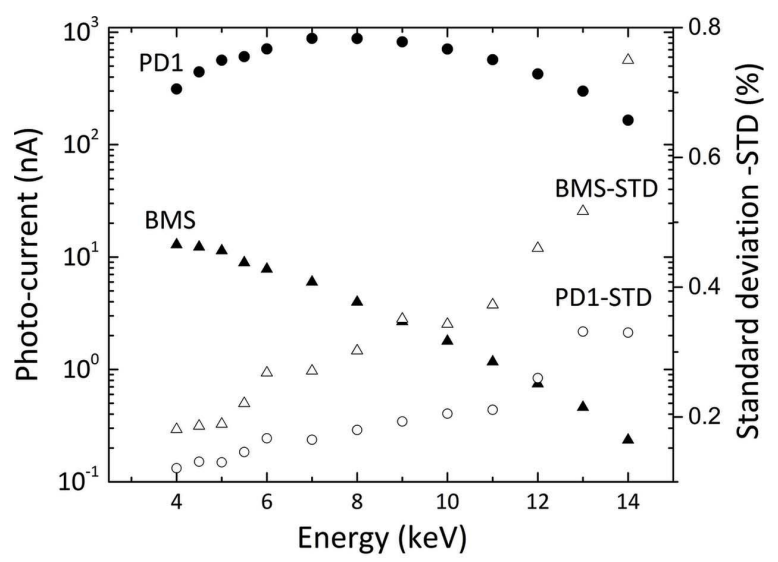

(a)

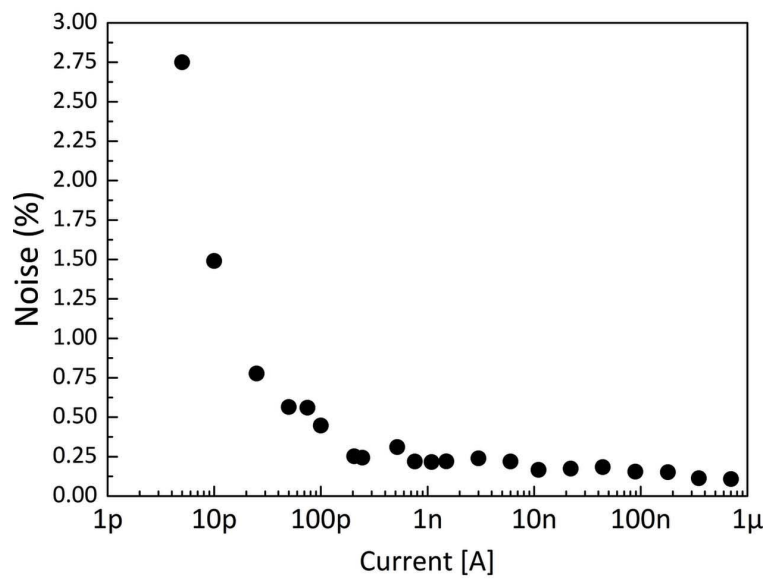

(b)

Figure 5

(a) Instantaneous (measured in buffer) photocurrent readings and respective standard deviations (\%) recorded at the energy regime from 4 to $14 \mathrm{keV}$ by the silicon photodiode PD1 and the diamond sensor (BMS) for Elettra operation at $2 \mathrm{GeV}$. (b) Variation of PD1 noise (\%) as a function of the recorded photocurrent. The standard deviation was determined from 200 consecutive measured values in the no-scan mode of the control software (Wrobel et al., 2016). 
the fixed $45^{\circ} / 45^{\circ}$ geometry. The PD1 values were properly corrected at each incident energy, $E_{0}$, for the respective attenuation in various beam path absorbers (including the RMX10), whereas the fluorescence data helped us to obtain through the PyMca the incident fluxes. The ratio of the $\operatorname{PD} 1\left(E_{0}\right) / \mathrm{PD} 1\left(E_{0}=10 \mathrm{keV}\right)$ photocurrent values over the respective ratio of incident fluxes $\Phi\left(E_{0}\right) / \Phi\left(E_{0}=10 \mathrm{keV}\right)$ is a quantity that depends only on the intrinsic absorption of the photodiode at the energies $E_{0}$ and $10 \mathrm{keV}$ and has no other dependence on the SDD detection solid angle and areal densities of the RMX10 constituent elements (Owen et al., 2009). Fig. 6 depicts two series of experimental data (obtained at 2 and $2.4 \mathrm{GeV}$ modes) and the fitted curve that has resulted from $\chi^{2}$ minimization of the experimental data. The obtained silicon PD1 thickness of $(296 \pm 5) \mu \mathrm{m}$ is in full accordance with the nominal value of $300 \mu \mathrm{m}$.

The determination of the thickness of the PD2 photodiode was carried out by using the dependence of the (PD1/BMS)/ (PD2/BMS) readings over the whole 4-14 keV energy regime, a quantity that depends only on the thicknesses of the two photodiodes. The $\chi^{2}$ minimization fitting procedure was also applied on the average values deduced from two different series of experimental data obtained at both operational modes of the storage ring. The fitting provided a PD2 thickness of $(83 \pm 2) \mu \mathrm{m}$, which is within the typical range declared by the manufacturer $(35-105 \mu \mathrm{m})$.

The Bruker SDD presents an excellent centroid and energy resolution stability over a high dynamic range of input count rates (up to $350 \mathrm{kcps}$ ). Its energy resolution deteriorates by about $20 \%$ when the shorter shaping time is used but generally does not depend on the input count rate, except in the case of the longer shaping time when some gradual worsening of its resolution is observed up to $5 \%$ as the input count rate is increased above $100 \mathrm{kcps}$. The input/output count-rate performance of the SDD is shown in Fig. 7, determined using

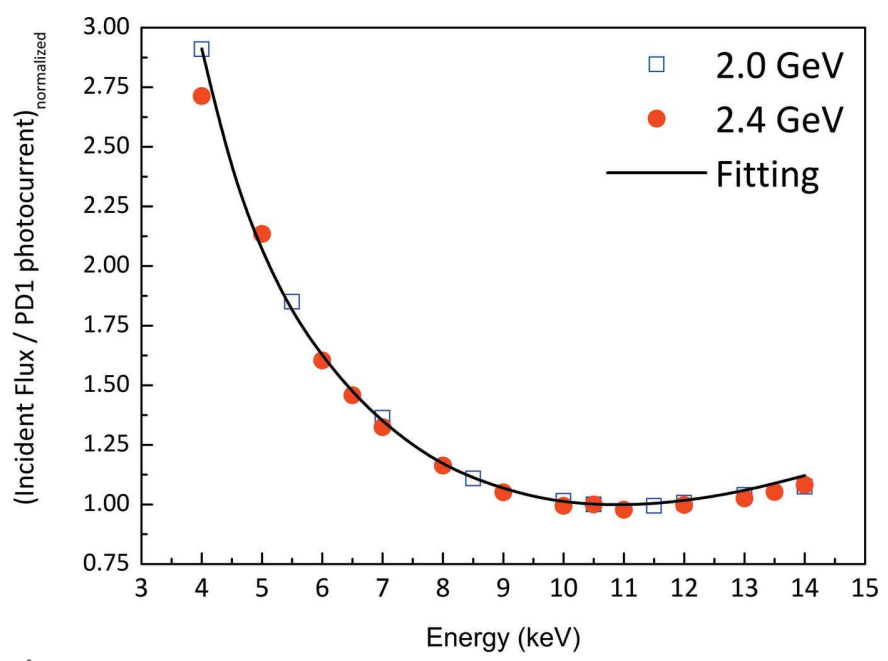

Figure 6

Experimental and fitted data for the dependence of the incident flux over the silicon photodiode current. The ratio at different energies was normalized with respect to its value at $10 \mathrm{keV}$. Through the fitting procedure, the thickness of the silicon photodiode was determined to be equal to: $(296 \pm 5) \mu \mathrm{m}$

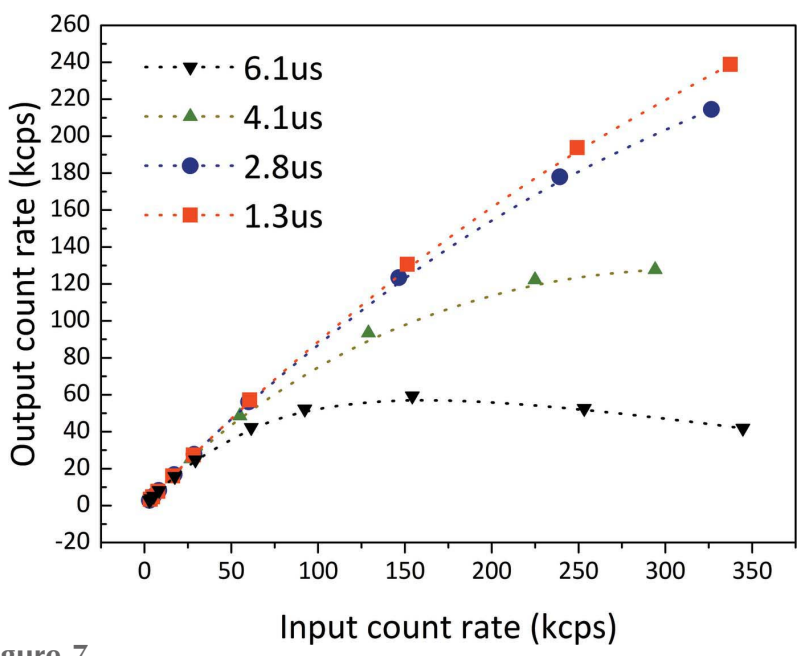

Figure 7

Input/output count-rate performance of the Bruker SDD at different peaking times determined using the dead-time correction implemented by means of the constant frequency zero peak.

the dead-time correction provided by means of the constant frequency zero peak.

\subsection{Incident beam fluxes and XRF elemental sensitivities}

An estimation of incident fluxes for different beam energies in the range $3.8-14 \mathrm{keV}$ is presented in Fig. 8 at two electron energy operation modes of the Elettra storage ring $(2 \mathrm{GeV}$, $309.1 \mathrm{~mA}$ and $2.4 \mathrm{GeV}, 159.4 \mathrm{~mA}$ ). The incident fluxes (photons $\mathrm{s}^{-1}$ ) normalized per $100 \mathrm{~mA}$ were determined using three datasets of PD1 readings (two at $2 \mathrm{GeV}$ and one at $2.4 \mathrm{GeV}$ ) based on the fitted thickness of the sensor, $296 \mu \mathrm{m}$, and the formulation described by Owen et al. (2009). Additional datasets of incident beam fluxes were also determined by means of the PyMca software using the RMX10 reference sample and a calibrated solid angle of detection. Generally, a

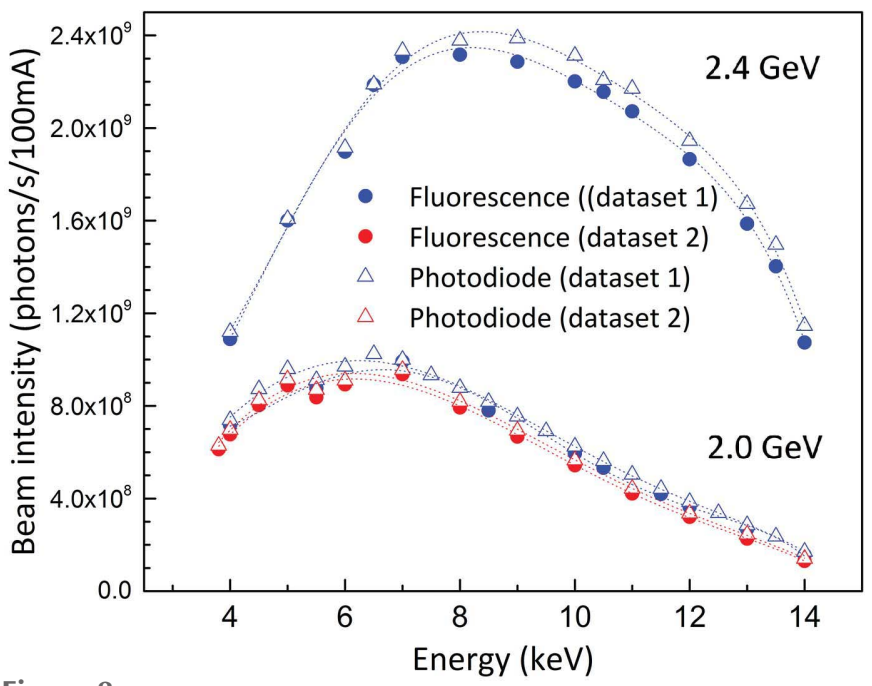

Figure 8

Estimation of the beam intensities for different incident beam energies $(3.8-14 \mathrm{keV})$ at two electron energy operation modes of the Elettra storage ring $(2 \mathrm{GeV}, 309.1 \mathrm{~mA}$ and $2.4 \mathrm{GeV}, 159.4 \mathrm{~mA})$. The beam intensities (photons $\mathrm{s}^{-1}$ ) were normalized per $100 \mathrm{~mA}$ ring current. 


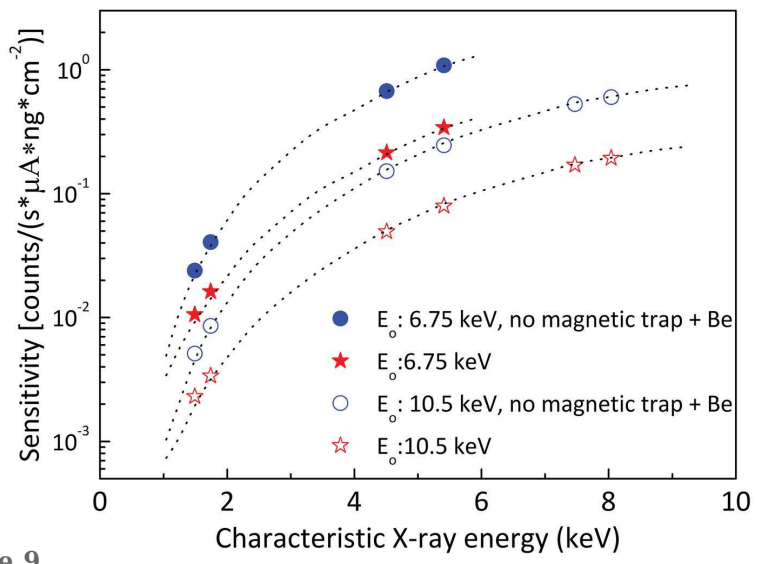

Figure 9

Experimental elemental sensitivities $\left[\mathrm{cps} /\left(\mu \mathrm{A} \mu \mathrm{g} \mathrm{cm} \mathrm{cm}^{-2}\right)\right]$ determined using the $K \alpha$ characteristic $\mathrm{X}$-ray intensities produced from the measurement of the RMX10 reference sample at 10.5 and $6.75 \mathrm{keV}$ excitation energies for both Bruker SDD configurations, with (no magnetic trap) and without the Be filter. The incident beam photocurrent refers to the silicon photodiode PD1 readings. The dotted curves represent respective elemental sensitivities calculated by means of the Monte Carlo program XMI-MSIM (Schoonjans et al., 2012). For this comparison, a normalization was performed between the experimental and MC-generated elemental sensitivities at the measured $\mathrm{Cu}-\mathrm{K} \alpha$ intensity.

very good consistency is observed among the independent determinations using different X-ray detectors (Fig. 8).

The elemental sensitivities of the setup, expressed in cps/ $\left(\mu \mathrm{A} \mu \mathrm{g} \mathrm{cm}^{-2}\right.$ ) units (with the incident beam current referring to the PD1 readings), were experimentally determined using the $K \alpha$ characteristic X-ray intensities produced from the measurement of the RMX10 reference sample at 10.5 and $6.75 \mathrm{keV}$ excitation energies for both Bruker SDD configurations, with (no magnetic trap) and without the Be filter (Fig. 9). The dotted curves represent the Monte Carlo (MC) calculated $K \alpha$ elemental sensitivities by means of the software program XMI-MSIM (Schoonjans et al., 2012). For this comparison, a normalization was performed between the experimental and MC generated elemental sensitivities at the measured value for $\mathrm{Cu}-\mathrm{K} \alpha$.

\section{Applications}

\subsection{Angular-dependent XRF (AD-XRF) and TXRF}

The Theta goniometer allows a high-precision stepwise variation of the angle formed between the incident beam direction and the sample surface in a large dynamic range, in practice between 0 and $90^{\circ}$. The energy-dispersive SDD used in the present setup configuration is placed at a fixed position perpendicular to the incident beam direction. In this case, the information depth which accounts for a specific percentage of the maximum analyte fluorescence intensity is expressed (in areal density units) proportional to the factor: $1 /\left\{\mu_{\mathrm{s}}\left(E_{\mathrm{o}}\right) / \sin \theta_{1}\right.$ $\left.+\mu_{\mathrm{s}}\left(E_{\mathrm{i}}\right) / \cos \theta_{1}\right\}$, where $\mu_{\mathrm{s}}$ denotes the sample mass attenuation coefficient at the energies for the exciting, $E_{0}$, and the analyte characteristic radiation, $E_{\mathrm{i}}$, respectively, and $\theta_{1}$ is the angle formed between the incident beam and the sample surface. In the above formula it has been assumed that the X-ray detector is placed perpendicular with respect to the incident beam direction. The strong dependence of the information depth with respect to the incident angle $\theta_{1}$ is exploited in angularresolved XRF analysis by measuring the analyte intensities at variable incident beam angles. In a very qualitative picture, as the incident angle decreases, the information depth is restricted much closer to the sample surface associating in this way the detected fluorescence intensity with the analyte concentration at different depths. Through an appropriate modelling of the composition of a stratified material, the determination of elemental concentration gradients is possible. The depth sensitivity of this methodology depends on the energy of the exciting and characteristic radiation, the sample matrix composition, whereas uncertainties are introduced due to the peak statistics, X-ray fundamental parameters and from the knowledge of the so-called geometrical factor $G\left(\theta_{1}\right)$ (Li et al., 2012), although the ratio method may overcome this necessity. The AD-XRF analysis is a suitable methodology for studying stratified materials with thicknesses of few micrometres (e.g. thin solar films) and up to very few tens of micrometres, for example two-layer systems like glazed ancient ceramics. Such studies are currently in progress by different research groups associated with the IAEA CRP project G42005.

The possibility to adjust the sample orientation so that the incident beam impinges at shallow angles (a few degrees) on the sample is also quite an interesting feature of the experimental setup, in particular when an infinitely thin and microscale heterogeneous sample is analysed. As a typical example, an airborne particulate matter sample deposited on a polycarbonate or Teflon backing medium of thickness a few $\mu \mathrm{m}$ can be considered. In this case, the shallow incident angle results in a significant increase of the beam footprint on the propagation plane (roughly according to the $\sin \theta_{1}^{-1}$ dependence), thus offering a much higher analyte signal output. It is interesting to observe in Fig. 10 the improvement attained in

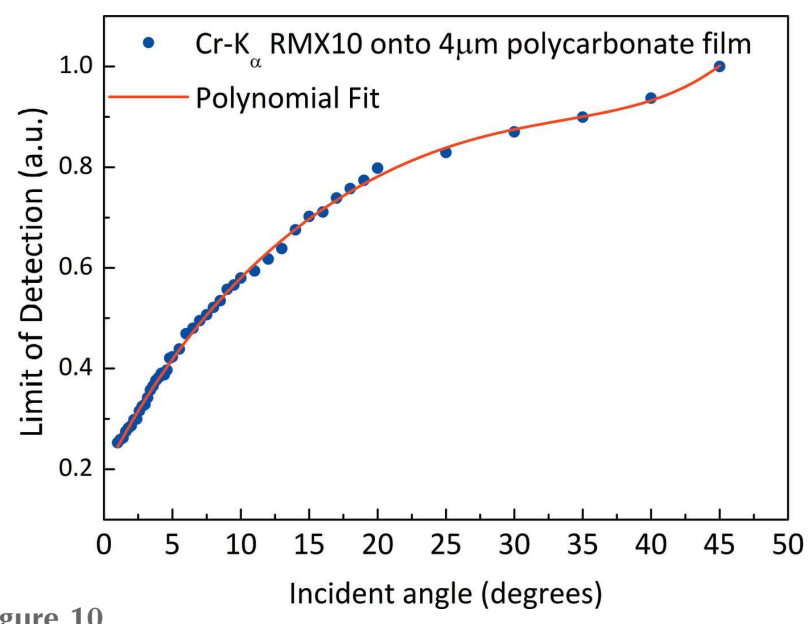

Figure 10

Relative improvement in the limits of detection for $\mathrm{Cr}$ as a function of incident angle. The analyzed sample is the RMX10 reference material deposited on $4 \mu \mathrm{m}$-thick polycarbonate filter (prepared in the same batch with the RMX10 onto $\mathrm{Si}_{3} \mathrm{~N}_{4}$ ), thus imitating to a good extent an airborne particulate matter filter material. 
the limits of detection for $\mathrm{Cr}$, if a small angle of a few degrees is selected for the analysis of the RMX10 sample deposited on the $4 \mu \mathrm{m}$-thick polycarbonate filter.

The analysis of the liquid samples is achieved by analyzing a dried residue $(\sim \mu \mathrm{L})$ on a reflecting surface under favourable excitation conditions (large beam footprint, double excitation, monochromatic and polarized beam) by fixing the incident angle of the exciting beam below the critical angle for external total reflection on the substrate medium (Tiwari et al., 2013). Under TXRF excitation conditions, limits of detection of less than $100 \mathrm{fg}$ absolute $\left(10 \mathrm{pg} \mathrm{ml}^{-1}\right)$ for Ni in NIST water 1640 have been reported (Fittschen et al., 2016). Using the IAEAXspe facility, Sanyal et al. (2017) demonstrated an improvement in the detection limits of $\mathrm{F}$ in comparison with a laboratory TXRF instrument, whereas Margui et al. (2017) measured trace elements in a digested human placenta sample.

\subsection{Combined GIXRF analysis and XRR}

The comprehensive characterization of thin films structural parameters of thickness from a few nm up to about $100 \mathrm{~nm}$ requires the synergistic application of GIXRF analysis and XRR methodologies. The Theta/2Theta goniometers of the IAEAXspe instrument are ideally suited for the application of such methodologies. For the demonstration of these analytical capabilities we have selected the results from the analysis of two thin film structures deposited on silicon substrates, a $\mathrm{W} / \mathrm{B}_{4} \mathrm{C}$ periodic multilayer (composed by 15 layers) and of a thin Fe film.

Details of the preparation of the $\mathrm{W} / \mathrm{B}_{4} \mathrm{C}$ periodic multilayer sample are reported elsewhere (Das et al., 2015). It has been deposited onto a polished $\mathrm{Si}(100)$ substrate at room temperature using a DC magnetron sputtering system. The $\mathrm{W} / \mathrm{B}_{4} \mathrm{C}$ multilayer has been previously characterized using laboratory XRR and at beamline BL-16 of the Indus-2 synchrotron facility at 10 and $12 \mathrm{keV}$ incident beam energies, respectively, using a combination of XRR and GIXRF methodologies (Das et al., 2015; Tiwari \& Das, 2016). Thus, this multilayer sample can be considered as a well characterized reference material to be used for an appropriate evaluation of the performance of the IAEAXspe instrument in similar studies. The Fe thin film has been manufactured by AXO Dresden $\mathrm{GmbH}$ and reference values for its microstructural parameters were determined by laboratory XRR. Both samples were analysed at $10.5 \mathrm{keV}$ incident energy with an angular step of Theta $=0.005^{\circ}, 2$ Theta $=0.01^{\circ}$ and measurement time equal to $10 \mathrm{~s}$ per step. The experimental GIXRF and XRR data are shown with open triangles and circles in Figs. 11 and 12, respectively. For the GIXRF measurements, the SDD front aperture was placed at a distance of 7 and $12 \mathrm{~mm}$ from the Fe thin and the $\mathrm{W} / \mathrm{B}_{4} \mathrm{C}$ multilayer samples, respectively. The adopted geometry, in combination with the small diameter of the SDD apertures, minimizes the variability of the geometrical factor $G\left(\theta_{1}\right)$ (Li et al., 2012) and maintains a small dynamic range for the dead-time correction within 0-20\%. The XRR measurements were carried out using the Si photodiode with the vertical slit of $200 \mu \mathrm{m}$ (PD5).

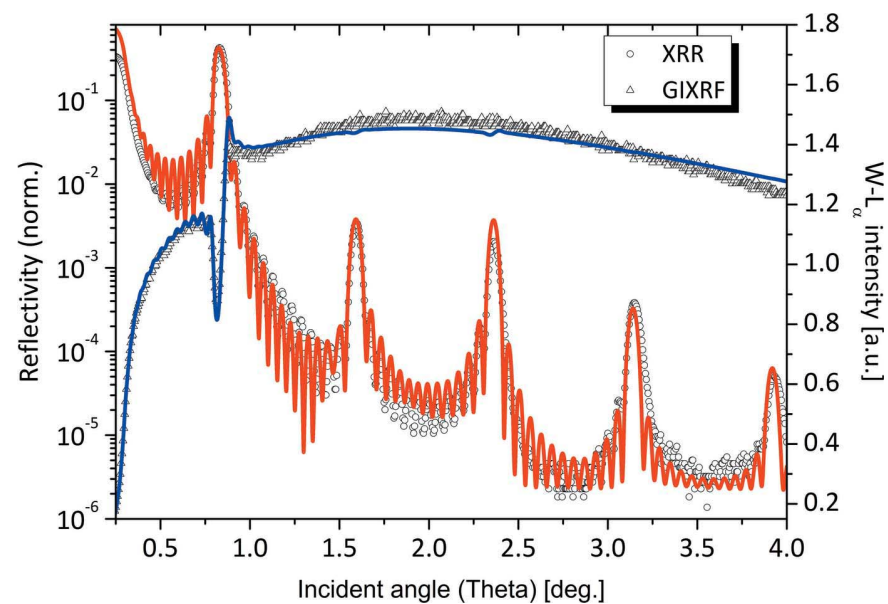

Figure 11

Experimental GIXRF/XRR data and respective fitted curves from the measurement of a W/B $\mathrm{B}_{4} \mathrm{C}$ periodic multilayer at $10.5 \mathrm{keV}$ incident energy. The GIXRF/XRR data were fitted simultaneously by means of a homedeveloped GIXRF/XRR analysis software.

The consistent fitting of GIXRF/XRR data has in the last few years attracted great interest from several groups (Tiwari \& Das, 2016; Ingerle et al., 2016; Brigidi \& Pepponi, 2017), by developing software packages and optimizing data analysis procedures. It is generally recognized that the fitting of the GIXRF/XRR data to deduce the microstructural properties (density, thickness, roughness) of thin layer systems is a rather complicated multi-parameter problem. The results of the fitting approach are affected by various experimental parameters involved in the measurements such as the counting statistics, the beam stability and divergence, the geometrical correction versus incident angle and by the lack of adequate knowledge for appropriate optical parameters which better describe real thin film structures instead of those derived from available databases.

For the fitting of the GIXRF/XRR data an in-housedeveloped software package was employed. Theoretical data

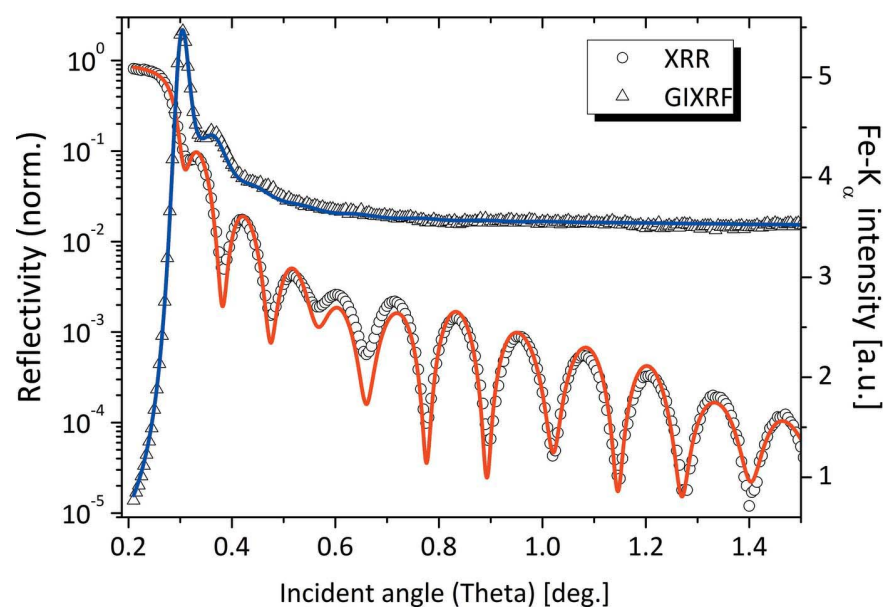

Figure 12

Experimental GIXRF/XRR data and respective fitted curves from the measurement of a Fe thin layer at $10.5 \mathrm{keV}$ incident energy. The GIXRF/ XRR data were fitted independently by means of a home-developed GIXRF/XRR analysis software. 
were generated following the formalism of de Boer et al. (1995) by means of Parratt's recursion method for the calculation of the transmitted and reflected electric field amplitudes and the Nevot-Croce correction for accounting for the roughness effect. The minimization procedure was based on a derivative-free and robust technique such as the differential evolution. Since the simultaneous fitting of the multiple GIXRF/XRR datasets is considered as a multi-objective minimization problem, the DEMO (differential evolution multi-objective) approach was adopted (Robic \& Filipic, 2005) as it has been proven to be very efficient in finding the global minimum. The value of each of the objective functions is calculated based on Pearson's chi-squared test, and the xraylib library (Schoonjans et al., 2011) was used as the resource for the needed X-ray fundamental parameters.

The analysis of the experimental GIXRF/XRR datasets has exploited for both studied samples different fitting strategies, such as the simultaneous or sequential fitting of the experimental data, and the optimization of the range limits for the fitted parameters. The best results are presented with solid curves in Figs. 11 and 12 . For the $\mathrm{W} / \mathrm{B}_{4} \mathrm{C}$ periodic multilayer, the simultaneous fitting of both the GIXRF/XRR data offered better description of the experimental data. In the case of the $\mathrm{Fe}$ thin layer, the introduction of a top $\mathrm{Fe}_{2} \mathrm{O}_{3}$ layer above the Fe metallic layer was necessary to improve the fitting results, whereas for this sample the XRR and the GIXRF datasets were fitted sequentially. The deduced fitted parameters are reported in Tables 3 and 4 with associated errors estimated from the observed variability of the fitted parameters around the global minimum. Uncertainties arising from the peak statistics of the W- $L \alpha$ and of Fe- $K \alpha$ characteristic X-ray lines and from the measurements precision (beam stability) are estimated to be generally less than $2 \%$. The results obtained for the multilayer sample are in very good agreement with previous analyses performed at the BL-16 beamline of Indus II (Das et al., 2015; Tiwari \& Das, 2016), whereas the obtained Fe thin film thickness also agrees well with the nominal thickness $(23.6 \mathrm{~nm})$ deduced by XRR at the manufacture premises.

\subsection{X-ray absorption measurements and combined methodologies}

The XRF beamline currently operates with a pair of $\operatorname{Si}(111)$ diffraction crystals that offers excellent energy resolution with a relative spectral bandwidth of $1.5 \times 10^{-4}$ in the energy regime from about 3.7 to $14 \mathrm{keV}$ (Jark et al., 2014). It should be noted that an upgrade is shortly planned with the commissioning of a pair of InSb diffraction crystals to extend X-ray absorption measurements down to $2 \mathrm{keV}(2.0-3.8 \mathrm{keV})$ with a relative spectral bandwidth of $3 \times 10^{-4}$ (Jark et al., 2014). The available spectral resolution combined with the IAEAXpe instrument capabilities offers powerful possibilities for chemical speciation studies of trace elements on the sample surface (TXRF-XANES) or within depth (XSWXANES and ADXRF-XANES). These complementary methodologies have already been exploited by several users
Table 3

Combined GIXRF/XRR determination of the microstructural properties (thickness, roughness and density) of a $\mathrm{B}_{4} \mathrm{C} / \mathrm{W}$ multilayer.

The fitting of the experimental data was performed using a home-developed GIXRF/XRR analysis software, whereas the results agree well with previous analyses performed at the BL-16 beamline of Indus II (Das et al., 2015; Tiwari \& Das, 2016).

\begin{tabular}{|c|c|c|c|c|}
\hline \multirow[b]{2}{*}{$\begin{array}{l}\text { Layer } \\
\text { material }\end{array}$} & \multirow[b]{2}{*}{ Periodicity } & \multicolumn{3}{|c|}{$\mathrm{B}_{4} \mathrm{C} / \mathrm{W}$ multilayer } \\
\hline & & $\begin{array}{l}\text { Thickness } \\
(\mathrm{nm})\end{array}$ & $\begin{array}{l}\text { Roughness } \\
(\mathrm{nm})\end{array}$ & $\begin{array}{l}\text { Density } \\
\left(\mathrm{g} \mathrm{cm}^{-3}\right)\end{array}$ \\
\hline $\mathrm{B}_{4} \mathrm{C}$ & 14 & $1.9 \pm 0.1$ & $0.2 \pm 0.1$ & $2.10 \pm 0.2$ \\
\hline W & & $2.4 \pm 0.2$ & $0.3 \pm 0.1$ & $16.0 \pm 0.2$ \\
\hline $\mathrm{B}_{4} \mathrm{C}$ & 1 & $2.1 \pm 0.6$ & $0.45 \pm 0.2$ & $2.3 \pm 0.2$ \\
\hline W & & $3.6 \pm 0.3$ & $0.55 \pm 0.2$ & $15.5 \pm 1.0$ \\
\hline $\mathrm{SiO}_{2}$ & 1 & $2.0 \pm 0.3$ & $0.5 \pm 0.2$ & $2.0 \pm 0.3$ \\
\hline
\end{tabular}

Table 4

Microstructural properties (thickness, roughness and density) of a Fe thin layer obtained as average values of the individual fitting of GIXRF and XRR data.

The fitting of the experimental data was performed using a home-developed GIXRF/XRR analysis software, whereas the results agree well with an informative value for the total Fe-layer thickness $(23.6 \mathrm{~nm})$ deduced by laboratory XRR at the manufacture premises.

\begin{tabular}{llll}
\hline & \multicolumn{3}{l}{ Fe thin film, average GIXRF/XRR results } \\
\cline { 2 - 4 } Layer material & $\begin{array}{l}\text { Thickness } \\
(\mathrm{nm})\end{array}$ & $\begin{array}{l}\text { Roughness } \\
(\mathrm{nm})\end{array}$ & $\begin{array}{l}\text { Density } \\
\left(\mathrm{g} \mathrm{cm}^{-3}\right)\end{array}$ \\
\hline $\mathrm{Fe}_{2} \mathrm{O}_{3}$ & $3.9 \pm 0.7$ & $0.5 \pm 0.1$ & $4.25 \pm 0.3$ \\
$\mathrm{Fe}$ & $23.7 \pm 0.7$ & $0.7 \pm 0.2$ & $6.8 \pm 0.2$ \\
$\mathrm{SiO}_{2}$ & $7.5 \pm 2.5$ & - & $1.6 \pm 0.2$ \\
\hline
\end{tabular}

associated with the IAEA CRP project G42005. X-ray absorption measurements have been carried out across the $K$-edge of several transition metals ( $\mathrm{Ti}, \mathrm{Cr}, \mathrm{Mn}, \mathrm{Fe}, \mathrm{Co}, \mathrm{Cu}$, $\mathrm{Zn}$ ) and metalloids (Ge, As, Se), and also across the $L_{3}$-edge of heavy elements $(\mathrm{W}, \mathrm{Hg})$ contained in various samples with interest in materials science, environmental studies, biomedicine, biology and cultural heritage.

An interesting application is related to the study of the ancient manufacture technology of the so-called Attic ceramics [see a typical sample in Fig. 4(a)] and refers to the determination of the Fe chemical environment within the top glazed layer (with thickness of $\sim 10-40 \mu \mathrm{m}$ ) formed onto the ceramic body (Lühl et al., 2014). The manufacture process of Attic black gloss is quite complex and its quality depends upon different factors such as the clay composition, grain size, firing temperature and the application of an oxidation-reductionoxidation firing cycle (Chaviara \& Aloupi-Siotis, 2016; Cianchetta et al., 2015; Lühl et al., 2014). The lower abundance of $\mathrm{Fe}$ (III) species within the black glaze has been suggested as a semi-quantitative indicator of its best quality (Lühl et al., 2014). Since the Fe- $K$ XANES analysis for the determination of the $\mathrm{Fe}(\mathrm{III}) / \mathrm{Fe}$ (II) abundance is affected by the pure $\mathrm{Fe}(\mathrm{III})$ contribution emanating from the ceramic body, a confocal setup has been previously employed to isolate the fluorescence emission from the black gloss layer and ceramic body, respectively (Lühl et al., 2014). An alternative methodology to tackle this analytical problem was developed utilizing the 


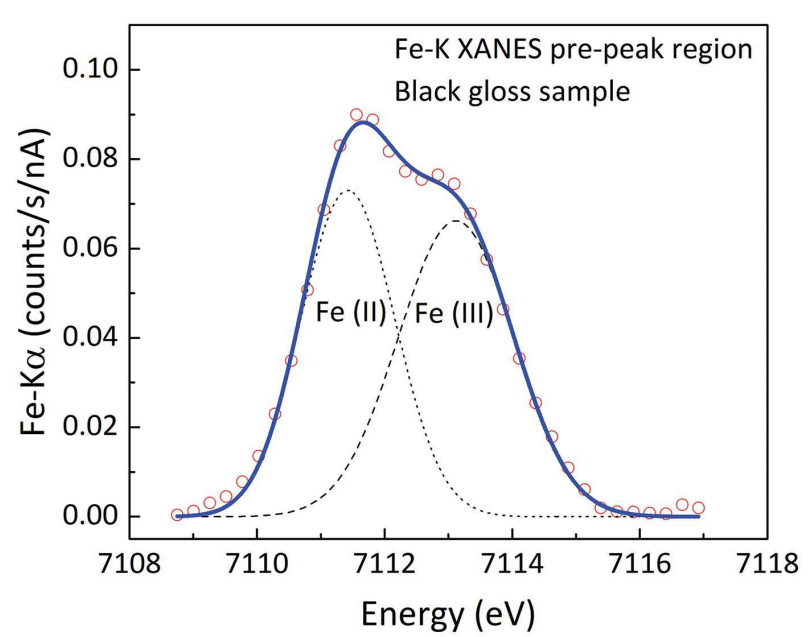

Figure 13

Pre-edge fitting of the Fe- $K$ edge XANES spectra acquired at $3^{\circ}$ incidence angle from an original Attic black gloss ceramic sample indicating the coexistence of two $\mathrm{Fe}$ oxidation states [ $\mathrm{Fe}(\mathrm{II}), \mathrm{Fe}(\mathrm{III})]$.

IAEAXspe instrument by employing a low incident angle for the exciting beam, thus restricting the incident beam path and fluorescence emission within the top black gloss layer. In Fig. 13 the pre-peak (7110-7118 eV) XANES spectrum of an Attic ceramic is shown acquired at the fluorescence mode, at $3^{\circ}$ incident angle, and with energy step $0.25 \mathrm{eV}, 1 \mathrm{~s} \mathrm{step}^{-1}$. The pre-peak region presents a double-peak structure due to the presence of both $\mathrm{Fe}(\mathrm{II})$ and $\mathrm{Fe}(\mathrm{III})$ species. The different content of the two iron oxides can provide information related to the firing conditions in which the phase transformations occurred and thus to discriminate recipes applied to produce imitations by different workshops in South Italy and Sicily (Pappalardo et al., 2016).

The ligand environment of $\mathrm{Hg}$ has been studied by means of $\mathrm{Hg}-L_{3}$ XANES analysis in the presence of Se in plants, fungi and animals, as well as in membranes used for the selective absorption of $\mathrm{Hg}$ (Kallithrakas-Kontos \& Foteinis, 2016). In the case of biological samples Hg-XANES is applied synergistically with scanning XRF analyses to obtain first full quantitative imaging of elemental distribution. As an example, Fig. 14 depicts fully quantitative $\mathrm{Se}$ and $\mathrm{Hg}$ distribution maps of a mushroom cap of bronze bolete (Boletus aereus) collected in the vicinity of a $\mathrm{Hg}$ mine in Idrija, Slovenia. The quantification procedure was conducted using dedicated software on the basis of calibration with pure element foils and fundamental parameters (Koren et al., 2013; Kump et al., 2011). It should be noted that samples are prepared by shock-freezing and freeze drying (Koren et al., 2013) in order to retain morphological and chemical properties and at the same time to be vacuum compatible. In the edible fungus Boletus aereus, $\mathrm{Hg}-L_{3}$ XANES spectra were recorded with $30 \mathrm{~s}$ per energy step $(0.5 \mathrm{eV})$ at several points of hymenophore (Fig. 14) and merged together. The best linear combination fit was obtained with $\mathrm{Hg}$ compounds as measured in plant and fungus models (Kodre et al., 2017) and $\mathrm{HgSe}$. In plants, $\mathrm{Hg}$ is mainly coordinated to two sulfur molecules with a small proportion bound to nitrogen. In fungi, however, a coordination of $\mathrm{Hg}$ to four

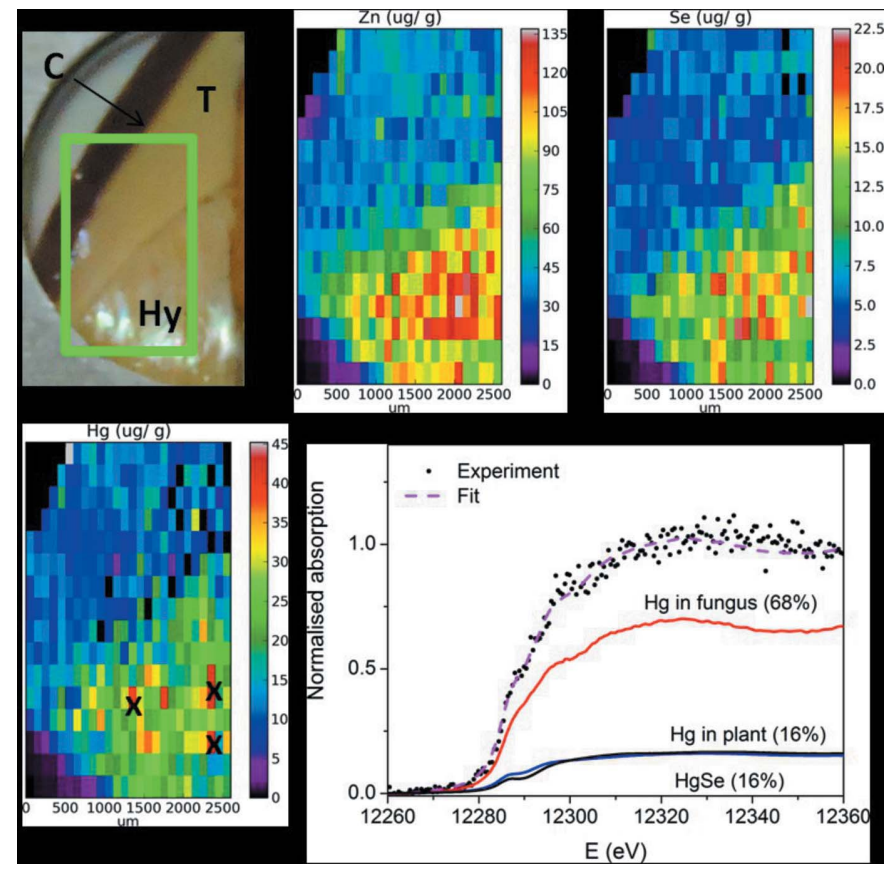

Figure 14

Quantitative maps of micro-element distribution in a mushroom (Boletus aereus) cap collected in the nearest vicinity of a $\mathrm{Hg}$ mine in Idrija, Slovenia. The cap consists of coloured cuticle (C), fleshy trama $(\mathrm{T})$ and hymenophore (Hy) consisting of numerous vertically arranged tubes that carry basidia. Microelements like $\mathrm{Zn}$ and $\mathrm{Se}$ as well as potentially hazardous $\mathrm{Hg}$ accumulate in hymenium. On the $\mathrm{Hg}$ map, points where $\mathrm{Hg}-L_{3}$ XANES spectra were recorded are labelled (X). The best linear combination fit was obtained by merging XANES spectra recorded in plant and fungal models (Kodre et al., 2017) and HgSe (courtesy of Iztok Arčon).

sulfur molecules is seen (Kodre et al., 2017). In B. aereus collected in the natural environment, $\mathrm{HgSe}$ coordination is also seen, that was not tracked before in plant and fungal tissues (Kodre et al., 2017).

The mobility and toxicity of trace elements is of particular interest in the study of environmental samples due to their potential impact on human health. XANES analysis has been applied for example for the determination of the oxidation state of As and Cr in coal fly ash samples (Santoso et al., 2016), but also for the investigation of the chemical environment of specific elements in airborne particulate matter (APM) thus assessing their potential impact and assisting in the identification of pollution sources. The possibility of collecting air particulates from specially designed cascade impactors (Sioutas, May) on silicon polished substrates offers the unique possibility to apply XANES analysis under the optimum TXRF excitation conditions. Using this TXRF-XANES methodology, chemical state analysis of $\mathrm{Cu}$ and $\mathrm{Zn}$ species has been carried out in size-fractionated APM samples (Osán et al., 2010).

Fig. 15 depicts $\mathrm{Zn}-K$ XANES spectra from an APM sample acquired with $10 \mathrm{~s}$ per energy step $(1 \mathrm{eV})$ together with reference spectra of $\mathrm{Zn}$ compounds. The APM sample was collected from the city of Paks, Hungary, using a nine-stage May-type cascade impactor onto a $20 \mathrm{~mm} \times 20 \mathrm{~mm} \mathrm{Si}$ wafer in 


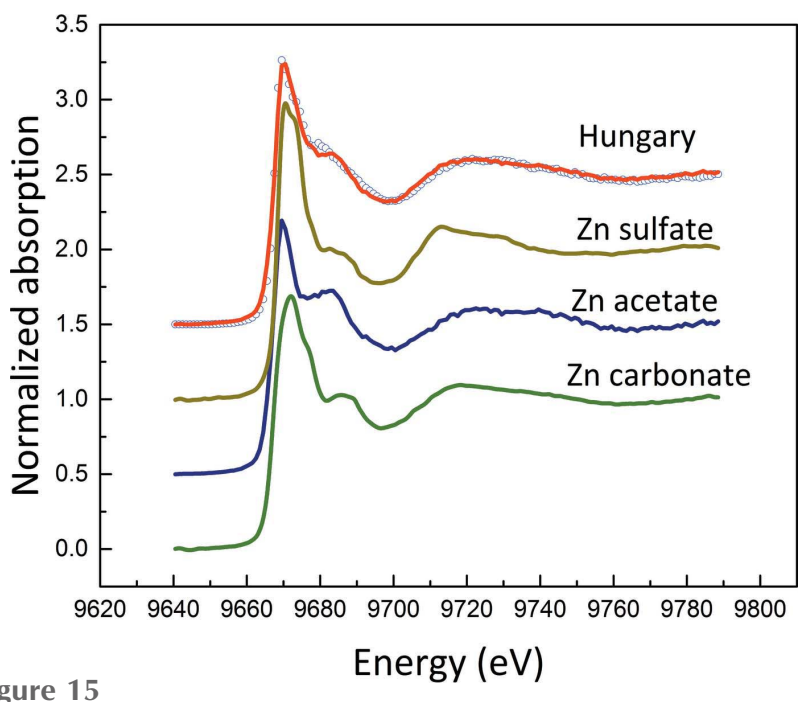

$\mathrm{Zn}-K$ TXRF-XANES spectrum measured from an airborne particulate matter sample (Hungary) together with reference spectra of $\mathrm{Zn}$ compounds. The sample was collected from the city of Paks, Hungary, using the nine-stage May-type cascade impactor $(0.3-0.6 \mu \mathrm{m}$ fraction) onto $20 \mathrm{~mm} \times 20 \mathrm{~mm} \mathrm{Si}$ wafer forming a stripe with $200-500 \mu \mathrm{m}$ width and measured at TXRF excitation geometry.

the form of a stripe with $200-500 \mu \mathrm{m}$ width representing the $0.3-0.6 \mu \mathrm{m}$ aerodynamic fraction of APM. The $\mathrm{Zn}$ amount on the $\mathrm{Si}$ wafer is estimated as $28.5 \mathrm{ng}\left(\sim 0.4 \mu \mathrm{g} \mathrm{cm}^{-2}\right)$ based on a TXRF spectrum recorded at $10 \mathrm{keV}$ excitation energy. The XANES spectrum was also acquired under the TXRF excitation condition. The XANES data were processed using the ATHENA tool (Ravel \& Newville, 2005) applying an appropriate self-absorption correction (Osán et al., 2010). Reasonable fitting based on a linear combination of standard XANES spectra revealed that $\mathrm{Zn}$ is contained mostly as organic bound (modelled with $\mathrm{Zn}$ acetate, 62\%), Zn sulfate (27\%) and $\mathrm{Zn}$ carbonate $(11 \%)$ indicating that the prominent source of $\mathrm{Zn}$ is galvanizing units at iron smelter facilities.

The low-vacuum environment that the main chamber of the IAEAXspe instrument may maintain with the introduction of the beryllium filter downstream is quite advantageous particularly when archaeological samples are analysed. As an example, the Co- $K$ XANES profile of an ancient glass bead is shown in Fig. 16, measured in the fluorescence mode as the sum of five repetitions, each taken with an energy step of $0.25 \mathrm{eV}$ around the Co- $K$ edge and with $8.5 \mathrm{~s} \mathrm{step}^{-1}$. The Co compound reference spectra shown in Fig. 16 were acquired in the transmission mode. The glass bead (Sokaras et al., 2009) presents a dark blue colouration due to minor $\mathrm{Co}$ and $\mathrm{Cu}$ amounts of $0.20 \% w / w$ and $0.47 \% w / w$, respectively (determined by SEM-EDS). It is evident that the cobalt in glass is present as $\mathrm{Co}(\mathrm{II})$, whereas its XANES profile resembles that measured from a modern smalt pigment.

\section{Conclusions and perspectives}

We have described the commissioning of a multi-technique IAEA experimental facility at the Elettra Sincrotrone Trieste. The experimental station allows a versatile combination of

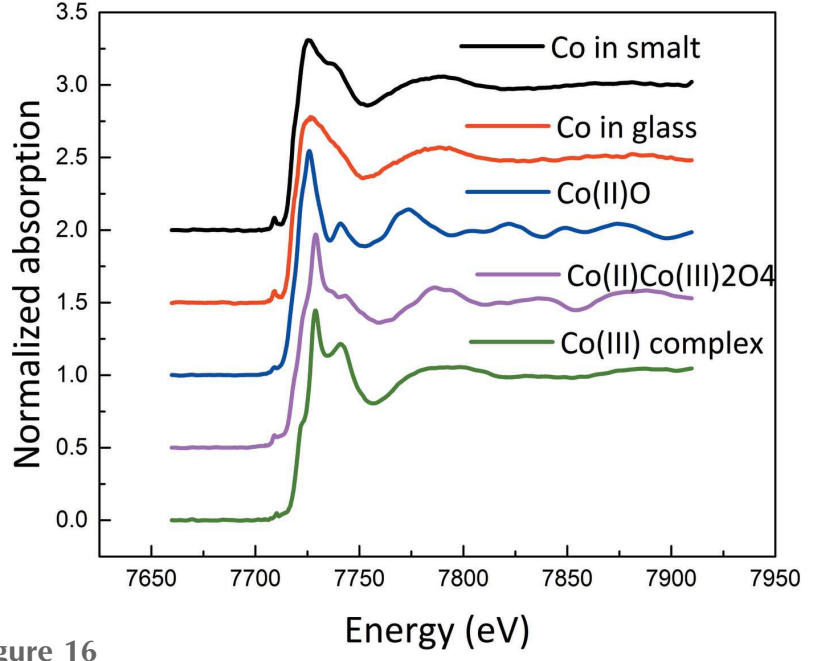

Co- $K$ XANES spectra acquired from an ancient glass bead, and different Co compound reference spectra. The XANES spectrum of the glass bead was recorded by the Bruker SDD in the fluorescence $\left(45^{\circ} / 45^{\circ}\right)$ mode, whereas the reference XANES spectra were obtained in the transmission mode by means of the Si photodiode PD1.

different analytical probes, e.g. typical sub-mm XRF, TXRF, GIXRF and X-ray absorption measurements in a single platform to perform chemical and structural characterization of various kinds of bulk and nanostructured materials under $\mathrm{UHV}$, as well as in a low-vacuum environment. By virtue of several state-of-the-art instrumentation and detector systems implemented in the experimental facility, it offers an attractive and competitive platform to accomplish a variety of research activities in the fields of archaeology, earth science and environmental studies, thin films and surface condensed matter physics applications etc., especially for those users who have limited resources and access to a synchrotron facility.

\section{Acknowledgements}

The authors are grateful to the Elettra Sincrotrone Trieste management and staff for their cooperation, excellent technical and scientific support and valuable discussions during execution of the project. The Physikalisch-Technische Bundesanstalt (PTB), Braunschweig und Berlin, and the Technical University of Berlin (TUB) are acknowledged for the provision of technical support during the first phase of the IAEAXspe development, installation and commissioning mainly carried out at the PTB laboratory in BESSY II, under the IAEA Technical Contract No. 7468. The authors would like also to thank Dr Francesco Paolo Romano, Dr Peter Kump, Dr Gangadhar Das and Professor Nikos Zacharias for their kind assistance in the present work. The end-users participating in the IAEA Coordinated Research Program (CRP) G42005 are also highly acknowledged for providing useful recommendations for improving the operation and performance of the IAEA endstation facility.

\section{References}

Adams, F., Janssens, K. \& Snigirev, A. (1998). J. Anal. At. Spectrom. 13, 319-331. 
Adams, F., Vekemans, B., Silversmit, G., De Samber, B. \& Vincze, L. (2011). Handbook of Nuclear Chemistry, pp. 1738-1758. Berlin: Springer

Awaji, N. (2004). Spectrochim. Acta B, 59, 1133-1139.

Awaji, N., Ozaki, S., Nishino, J., Noguchi, S., Yamamoto, T., Syoji, T., Yamagami, M., Kobayashi, A., Hirai, Y., Shibata, M., Yamaguchi, K., Liu, K. Y., Kawado, S., Takahashi, M., Yasuami, S., Konomi, I., Kimura, S., Hirai, Y., Hasegawa, M., Komiya, S., Hirose, T. \& Okajima, T. (2000). Jpn. J. Appl. Phys. 39, L1252-L1255.

Becker, C., Pagels, M., Zachäus, C., Pollakowski, B., Beckhoff, B., Kanngießer, B. \& Rech, B. (2013). J. Appl. Phys. 113, 044519.

Beckhoff, B. (2008). J. Anal. At. Spectrom. 23, 845.

Beckhoff, B., Fliegauf, R., Kolbe, M., Müller, M., Weser, J. \& Ulm, G. (2007). Anal. Chem. 79, 7873-7882.

Boer, D. K. G. de, Leenaers, A. J. G. \& van den Hoogenhof, W. W. (1995). X-ray Spectrom. 24, 91-102.

Bohlen, A. von (2009). Spectrochim. Acta B, 64, 821-832.

Brigidi, F. \& Pepponi, G. (2017). X-ray Spectrom. 45, 19-24.

Cezar, J. C., Souza-Neto, N. M., Piamonteze, C., Tamura, E., Garcia, F., Carvalho, E. J., Neueschwander, R. T., Ramos, A. Y., Tolentino, H. C. N., Caneiro, A., Massa, N. E., Martinez-Lope, M. J., Alonso, J. A. \& Itié, J.-P. (2010). J. Synchrotron Rad. 17, 93-102.

Chang, W., Der, Hung, H. H., Dann, T. E., Huang, T. W. \& Wu, S. Y. (2004). Chin. J. Phys. 42, 607-618.

Chaviara, A. \& Aloupi-Siotis, E. (2016). J. Arch. Sci. Rep. 7, 510-518.

Cianchetta, I., Trentelman, K., Maish, J., Saunders, D., Foran, B., Walton, M., Sciau, P., Wang, T., Pouyet, E., Cotte, M., Meirer, F., Liu, Y., Pianetta, P. \& Mehta, A. (2015). J. Anal. At. Spectrom. 30, 666-676.

Das, G., Kane, S. R., Khooha, A., Singh, A. K. \& Tiwari, M. K. (2015). Rev. Sci. Instrum. 86, 055102.

Eisenhauer, D., Pollakowski, B., Baumann, J., Preidel, V., Amkreutz, D., Rech, B., Back, F., Rudigier-Voigt, E., Beckhoff, B., Kanngießer, B. \& Becker, C. (2015). Phys. Status Solidi A, 212, 529-534.

Fittschen, U., Guilherme, A., Böttger, S., Rosenberg, D., Menzel, M., Jansen, W., Busker, M., Gotlib, Z. P., Radtke, M., Riesemeier, H., Wobrauschek, P. \& Streli, C. (2016). J. Synchrotron Rad. 23, 820824.

Hirai, Y., Yasuami, S., Kobayashi, A., Hirai, Y., Nishino, J., Shibata, M., Yamaguchi, K., Liu, K. Y., Kawado, S., Yamamoto, T., Noguchi, S., Takahashi, M., Konomi, I., Kimura, S., Hasegawa, M., Awaji, N., Komiya, S., Hirose, T., Ozaki, S., Okajima, T., Ishikawa, T. \& Kitamura, H. (2004). Nucl. Instrum. Methods Phys. Res. A, 521, 538-548.

Hirosawa, I., Koganezawa, T. \& Ishii, H. (2011). IEICE Trans. Electron. 94, 1755-1759.

Hirosawa, I., Uehara, Y., Sato, M. \& Umesaki, N. (2004). J. Ceram. Soc. Japan, 112, 1476-1478.

Hönicke, P., Detlefs, B., Müller, M., Darlatt, E., Nolot, E., Grampeix, H. \& Beckhoff, B. (2015). Phys. Status Solidi A, 212, 523-528.

Ingerle, D., Pepponi, G., Meirer, F., Wobrauschek, P. \& Streli, C. (2016). Spectrochim. Acta B, 118, 20-28.

Ingerle, D., Schiebl, M., Streli, C. \& Wobrauschek, P. (2014). Rev. Sci. Instrum. 85, 083110.

Janssens, K., Proost, K. \& Falkenberg, G. (2004). Spectrochim. Acta B, 59, 1637-1645.

Jark, W., Eichert, D., Luehl, L. \& Gambitta, A. (2014). Proc. SPIE, 9207, 1-12.

Kallithrakas-Kontos, N. \& Foteinis, S. (2016). Curr. Anal. Chem. 12, 22-36.

Kanngießer, B., Malzer, W. \& Reiche, I. (2003). Nucl. Instrum. Methods Phys. Res. B, 211, 259-264.

Kayser, Y., Sá, J. \& Szlachetko, J. (2015). Anal. Chem. 87, 1081510821.

Kodre, A., Arčon, I., Debeljak, M., Potisek, M., Likar, M. \& VogelMikuš, K. (2017). Environ. Exp. Bot. 133, 12-23.

Koren, S., Arčon, I., Kump, P., Nečemer, M. \& Vogel-Mikuš, K. (2013). Plant Soil, 370, 125-148.
Krämer, M., Dietsch, R., Holz, T., Weissbach, D., Falkenberg, G., Simon, R., Fittschen, U., Krugmann, T., Kolbe, M., Müller, M. \& Beckhoff, B. (2011). JCPDS Int. Cent. Diffr. Data, pp. 299-304.

Krämer, M., von Bohlen, A., Sternemann, C., Paulus, M. \& Hergenröder, R. (2006). J. Anal. At. Spectrom. 21, 1136-1142.

Krywka, C., Paulus, M., Sternemann, C., Volmer, M., Remhof, A., Nowak, G., Nefedov, A., Pöter, B., Spiegel, M. \& Tolan, M. (2006). J. Synchrotron Rad. 13, 8-13.

Krywka, C., Sternemann, C., Paulus, M., Volmer, M., Berges, U. \& Tolan, M. (2007). AIP Conf. Proc. 879, 875-878.

Kump, P., Nečemer, M., Rupnik, Z., Pelicon, P., Ponikvar, D., VogelMikuš, K., Regvar, M. \& Pongrac, P. (2011). Improvement of the $X R F$ quantification and enhancement of the combined applications by EDXRF and micro-PIXE (IAEA-TECDOC-1669), pp. 101-110. International Atomic Energy Agency.

Leenaers, A. J. G. \& de Boer, D. K. G. (1997). X-ray Spectrom. 26, $115-121$.

Lemelle, L., Simionovici, A., Schoonjans, T., Tucoulou, R., Enrico, E., Salomé, M., Hofmann, A. \& Cavalazzi, B. (2017). TrAC Trends Anal. Chem. 91, 104-111.

Li, W., Zhu, J., Ma, X., Li, H., Wang, H., Sawhney, K. J. S. \& Wang, Z. (2012). Rev. Sci. Instrum. 83, 053114.

Lombi, E., de Jonge, M. D., Donner, E., Kopittke, P. M., Howard, D. L., Kirkham, R., Ryan, C. G. \& Paterson, D. (2011). PLoS One, 6, e20626.

Lubeck, J., Beckhoff, B., Fliegauf, R., Holfelder, I., Hönicke, P., Müller, M., Pollakowski, B., Reinhardt, F. \& Weser, J. (2013). Rev. Sci. Instrum. 84, 045106.

Lubeck, J., Bogovac, M., Boyer, B., Detlefs, B., Eichert, D., Fliegauf, R., Grötzsch, D., Holfelder, I., Hönicke, P., Jark, W., Kaiser, R. B., Kanngießer, B., Karydas, A. G., Leani, J. J., Lépy, M. C., Luhl, L., Ménesguen, Y., Migliori, A., Müller, M., Pollakowski, B., Spanier, M., Sghaier, H., Ulm, G., Weser, J. \& Beckhoff, B. (2016). AIP Conf. Proc. 1741, 1-5.

Lubeck, J., Weser, J. \& Beckhoff, B. (2015). Report of the Physikalisch Technische Bundesanstalt (PTB) Braunschweig und Berlin, under the IAEA Technical contract No. 17468, 2015, 0-34.

Lühl, L., Hesse, B., Mantouvalou, I., Wilke, M., Mahlkow, S., AloupiSiotis, E. \& Kanngießer, B. (2014). Anal. Chem. 86, 6924-6930.

Marguí, E., Ricketts, P., Fletcher, H., Karydas, A. G., Migliori, A., Leani, J. J., Hidalgo, M., Queralt, I. \& Voutchkov, M. (2017). Spectrochim. Acta B, 130, 53-59.

Maurizio, C., Rovezzi, M., Bardelli, F., Pais, H. G. \& D'Acapito, F. (2009). Rev. Sci. Instrum. 80, 063904.

Meirer, F., Singh, A., Pianetta, P., Pepponi, G., Meirer, F., Streli, C. \& Homma, T. (2010). TrAC Trends Anal. Chem. 29, 479-496.

Ménesguen, Y., Boyer, B., Rotella, H., Lubeck, J., Weser, J., Beckhoff, B., Grötzsch, D., Kanngießer, B., Novikova, A., Nolot, E. \& Lépy, M.-C. (2017). X-ray Spectrom. 46, 303-308.

Ohashi, H., Yamazaki, H., Yumoto, H., Koyama, T., Senba, Y., Takeuchi, T., Terada, Y., Suzuki, M., Kawamura, N., Mizumaki, M., Nariyama, N., Takeshita, K., Fujiwara, A., Uruga, T., Goto, S., Yamamoto, M., Takata, M. \& Ishikawa, T. (2013). J. Phys. Conf. Ser. 425, 052018.

Osán, J., Meirer, F., Groma, V., Török, S., Ingerle, D., Streli, C. \& Pepponi, G. (2010). Spectrochim. Acta B, 65, 1008-1013.

Owen, R. L., Holton, J. M., Schulze-Briese, C. \& Garman, E. F. (2009). J. Synchrotron Rad. 16, 143-151.

Pagels, M., Reinhardt, F., Pollakowski, B., Roczen, M., Becker, C., Lips, K., Rech, B., Kanngießer, B. \& Beckhoff, B. (2010). Nucl. Instrum. Methods Phys. Res. B, 268, 370-373.

Pappalardo, L., Barresi, S., Biondi, G., Caliri, C., Caruso, F., Catalano, R., Lamagna, G., Manenti, G. A., Monterosso, G., Orlando, A., Rizzo, F., Romano, F. P. \& Santos, H. C. (2016). X-ray Spectrom. 45, 258-262.

Paulus, M., Lietz, D., Sternemann, C., Shokuie, K., Evers, F., Tolan, M., Czeslik, C. \& Winter, R. (2008). J. Synchrotron Rad. 15, 600605. 
Pollakowski, B., Hoffmann, P., Kosinova, M., Baake, O., Trunova, V., Unterumsberger, R., Ensinger, W. \& Beckhoff, B. (2013). Anal. Chem. 85, 193-200.

Ravel, B. \& Newville, M. (2005). J. Synchrotron Rad. 12, 537-541.

Riesemeier, H., Ecker, K., Görner, W., Müller, B. R., Radtke, M. \& Krumrey, M. (2005). X-ray Spectrom. 34, 160-163.

Robic, T. \& Filipic, B. (2005). Proceedings of the Third International Conference on Evolutionary Multi-Criterion Optimization (EMO 2005), Vol. 3410 of Lecture Notes in Computer Science, edited by C. A. Coello Coello, A. Hernández Aguirre \& E. Zitzler, pp. 520533. Berlin, Heidelberg: Springer-Verlag.

Santoso, M., Lestiani, D. D., Damastuti, E., Kurniawati, S., Bennett, J. W., Leani, J. J., Czyzycki, M., Migliori, A., Osán, J. \& Karydas, A. G. (2016). J. Radioanal. Nucl. Chem. 309, 413-419.

Sanyal, K., Kanrar, B., Misra, N. L., Czyzycki, M., Migliori, A. \& Karydas, A. G. (2017). X-ray Spectrom. 46, 164-170.

Schoonjans, T., Brunetti, A., Golosio, B., Sanchez del Rio, M., Solé, V. A., Ferrero, C. \& Vincze, L. (2011). Spectrochim. Acta B, 66, 776784.

Schoonjans, T., Vincze, L., Solé, V. A., Sanchez del Rio, M., Brondeel, P., Silversmit, G., Appel, K. \& Ferrero, C. (2012). Spectrochim. Acta $B, 70,10-23$.

Simon, R., Buth, G. \& Hagelstein, M. (2003). Nucl. Instrum. Methods Phys. Res. B, 199, 554-558.

Singh, A., Luening, K., Brennan, S., Homma, T., Kubo, N., Nowak, S. H. \& Pianetta, P. (2017). J. Synchrotron Rad. 24, 283-287.

Sokaras, D., Karydas, A. G., Oikonomou, A., Zacharias, N., Beltsios, K. \& Kantarelou, V. (2009). Anal. Bioanal. Chem. 395, 2199-2209.

Solé, V. A., Papillon, E., Cotte, M., Walter, P. \& Susini, J. (2007). Spectrochim. Acta B, 62, 63-68.

Somogyi, A., Tucoulou, R., Martinez-Criado, G., Homs, A., Cauzid, J., Bleuet, P., Bohic, S. \& Simionovici, A. (2005). J. Synchrotron Rad. 12, 208-215.

Spanier, M., Herzog, C., Grötzsch, D., Kramer, F., Mantouvalou, I., Lubeck, J., Weser, J., Streeck, C., Malzer, W., Beckhoff, B. \& Kanngießer, B. (2016). Rev. Sci. Instrum. 87, 035108.

Sparks, C. J. (1980). Synchrotron Radiation Research, edited by H. Winick and S. Doniach, pp. 459-512. New York: Plenum Press.
Streli, C., Wobrauschek, P., Meirer, F. \& Pepponi, G. (2008). J. Anal. At. Spectrom. 23, 792.

Terada, Y., Tanida, H., Uruga, T., Takeuchi, A., Suzuki, Y., Goto, S., McNulty, I., Eyberger, C. \& Lai, B. (2011). AIP Conf. Proc. 1365, 172-175.

Tiwari, M. K. \& Das, G. (2016). X-ray Spectrom. 45, 212-219.

Tiwari, M. K., Gupta, P., Sinha, A. K., Kane, S. R., Singh, A. K., Garg, S. R., Garg, C. K., Lodha, G. S. \& Deb, S. K. (2013). J. Synchrotron Rad. 20, 386-389.

Tolentino, H., Cezar, J. C., Cruz, D. Z., Compagnon-Cailhol, V., Tamura, E. \& Martins Alves, M. C. (1998). J. Synchrotron Rad. 5, 521-523.

Tolentino, H. C. N., Ramos, A. Y., Alves, M. C. M., Barrea, R. A., Tamura, E., Cezar, J. C. \& Watanabe, N. (2001). J. Synchrotron Rad. 8, 1040-1046.

Ulrich, O., Biquard, X., Bleuet, P., Geaymond, O., Gergaud, P., Micha, J. S., Robach, O. \& Rieutord, F. (2011). Rev. Sci. Instrum. 82, 033908 .

Uruga, T., Tanida, H., Yoneda, Y., Takeshita, K., Emura, S., Takahashi, M., Harada, M., Nishihata, Y., Kubozono, Y., Tanaka, T., Yamamoto, T., Maeda, H., Kamishima, O., Takabayashi, Y., Nakata, Y., Kimura, H., Goto, S. \& Ishikawa, T. (1999). J. Synchrotron Rad. 6, 143-145.

Vincze, L., Vekemans, B., Brenker, F. E., Falkenberg, G., Rickers, K., Somogyi, A., Kersten, M. \& Adams, F. (2004). Anal. Chem. 76, 6786-6791.

Winarski, R. P., Holt, M. V., Rose, V., Fuesz, P., Carbaugh, D., Benson, C., Shu, D., Kline, D., Stephenson, G. B., McNulty, I. \& Maser, J. (2012). J. Synchrotron Rad. 19, 1056-1060.

Wrobel, P. M., Bogovac, M., Sghaier, H., Leani, J. J., Migliori, A., Padilla-Alvarez, R., Czyzycki, M., Osan, J., Kaiser, R. B. \& Karydas, A. G. (2016). Nucl. Instrum. Methods Phys. Res. A, 833, 105109.

Yang, X., Li, W., Zhu, J., Li, X. \& Wang, Z. (2013). Proc. SPIE, 9068 , 1-6.

Yuying, H., Yingrong, W., Limin, Z., Guangcheng, L., Wei, H., Lizhen, Y., Jiapei, C., Jiangfu, L., Tongcun, Z. \& Enhua, C. (2001). Spectrochim. Acta B, 56, 2057-2062. 